\title{
Implementation of Pseudo J-Integral Based Paris' Law for Fatigue Cracking in Asphalt Mixtures and Pavements ${ }^{1}$
}

\author{
Xue Luo ${ }^{\mathrm{a}, *}$, Yuqing Zhang ${ }^{\mathrm{b}}$, Robert L. Lytton ${ }^{\mathrm{c}}$ \\ ${ }^{a}$ Texas A\&M Transportation Institute, College Station, TX, USA \\ Address: CE/TTI Bldg 508B, 3135 TAMU, College Station, Texas 77843-3135 \\ ${ }^{b}$ School of Engineering and Applied Science, Aston University, Birmingham, UK \\ Address: MB153A, Aston Triangle, Birmingham, B4 7ET \\ 'Zachry Department of Civil Engineering, Texas A\&M University, College \\ Station, TX, USA
}

Address: CE/TTI Bldg. 503A, 3136 TAMU, College Station, Texas 77843-3136

*Corresponding author. Tel.: 1-979-458-8535. Fax: 1-979-845-0278

Email addresses:

xueluo@tamu.edu (Xue Luo)

y.zhang10@aston.ac.uk (Yuqing Zhang)

r-lytton@civil.tamu.edu (Robert L. Lytton)

\section{Abstract}

Pavement analysis and design for fatigue cracking involves a number of practical problems like material assessment/screening and performance prediction. A mechanics-aided method can answer these questions with satisfactory accuracy in a convenient way when it is appropriately implemented. This paper presents two techniques to implement the pseudo J-integral based Paris' law to evaluate and predict fatigue cracking in asphalt mixtures and pavements. The first technique, quasi-elastic simulation, provides a rational and appropriate reference modulus for the pseudo analysis (i.e., viscoelastic to elastic conversion) by making use of the widely used material property: dynamic modulus. The physical significance of the quasi-elastic simulation is clarified. Introduction of this technique facilitates the implementation of the fracture mechanics models as well as continuum damage mechanics models to characterize fatigue cracking in asphalt pavements. The second technique about modeling fracture coefficients of the pseudo J-integral based Paris' law simplifies the prediction of fatigue cracking without performing fatigue tests. The developed prediction models for the fracture coefficients rely on readily available mixture design properties that directly affect the fatigue performance, including the relaxation modulus, air void content, asphalt binder content, and aggregate gradation. Sufficient data are collected to develop

\footnotetext{
1 This is an Accepted Manuscript of an article published by Springer in Journal of Materials and Structures. The final publication is available online via http://dx.doi.org/10.1617/s11527$\underline{015-0750-z}$
} 
such prediction models and the R-squared values are around 0.9. The presented case studies serve as examples to illustrate how the pseudo J-integral based Paris' law predicts fatigue resistance of asphalt mixtures and assesses fatigue performance of asphalt pavements. Future applications include the estimation of fatigue life of asphalt mixtures/pavements through a distinct criterion that defines fatigue failure by its physical significance.

Keywords: asphalt mixtures; fatigue cracking; quasi-elastic simulation; reference modulus; pseudo J-integral; Paris’ law; fracture coefficients

\section{Introduction}

Fatigue cracking in asphalt pavements has always been a concern of pavement analysts and designers. It is commonly agreed that asphalt mixtures with satisfactory fatigue resistance are critical for high-performance pavements in terms of fatigue cracking. To quantify and compare fatigue resistance of different asphalt materials, the most popular technique is the experimental investigation, i.e. fatigue testing that resembles service loading in an environment representative of service conditions of pavements. Such tests include the repeated flexural bending test, indirect tension test, and uniaxial cyclic test, etc. The approach to interpret the test data varies from simple statistical regressions to more complex mechanics-based characterizations. The statistical regressions refer to the techniques that relate the fatigue resistance of tested materials to the stress/strain or mechanical properties. This empirical approach is straightforward. In particular, the strain based prediction model relates the fatigue life of an asphalt pavement directly to its response. The mechanical properties are also used in the prediction of fatigue life or fatigue cracking, such as the dissipated strain energy (Rowe, 1993) and the fracture energy as the sum of the strain energy and dissipated strain energy (Kim and Wen, 2002).

Compared to these empirical strain or property based prediction methods, a more physically-based approach is to incorporate mechanics into the experimental investigation of the fatigue resistance of asphalt materials. More specifically, the test data are translated to fracture properties by introducing fracture mechanics or damage indexes through continuum damage mechanics. Fracture mechanics is a branch of mechanics that especially describes the behavior of cracks in solids. The Paris' law is by far the most widely used fracture mechanics tool to characterize crack growth by fatigue: 


$$
\frac{d c}{d N}=A(\Delta K)^{n} \quad \text { or } \quad \frac{d c}{d N}=A(\Delta J)^{n}
$$

where ${ }_{c}$ is the crack length; $N$ is the number of load repetition; $\Delta K$ is the range of stress intensity factor; $\Delta J$ is the J-integral range; and $A$ and $n$ are fracture coefficients associated with $\Delta K$ or $\Delta J$. The increase of the crack length with the number of load repetitions captures the physical process of fatigue cracking. The physical significance of $K$ is that it quantifies the stress state near the crack tip. The physical significance of $J$ is that it is the energy release rate that quantifies the rate of the change of the potential energy due to the crack growth. There have been numerous applications of the Paris' law in the field of asphalt pavements (e.g. Lytton et al., 1993; Jacobs, 1995; Zhang et al., 2001; Kuai et al., 2009). Besides fracture mechanics, continuum damage mechanics is another tool to study cracking, which treats material damage within the framework of continuum mechanics and targets the dispersed nature of cracking. The continuum damage mechanics employs damage state variables to represent material deterioration at the macroscale (e.g. stiffness degradation) due to damage evolution. It can also account for the evolving microstructure when damage progresses in a material. Applications of continuum damage mechanics in asphalt material characterization and damage modeling have given rise to many analytical solutions (e.g. Park et al., 1996; Christensen and Bonaquist, 2005), and also facilitated numerical simulations of damage development (e.g. Collop et al., 2003; Dai et al., 2005).

The use of mechanics offers a more fundamental description of fatigue cracking than the empirical approach. However, the empirical strain based approach still dominates most pavement designs. For example, the fatigue cracking prediction model incorporated in the 2002 Mechanistic-Empirical Pavement Design Guide (MEPDG) (ARA, 2004) is:

$$
N_{f}=\beta_{f 1} k_{1}\left(\varepsilon_{t}\right)^{-\beta_{f 2} k_{2}}(E)^{-\beta_{f 3} k_{3}}
$$

where $N_{f}$ is the allowable number of load repetitions for an asphalt pavement; $\varepsilon_{t}$ is the tensile strain at critical locations; $E$ is the dynamic modulus of asphalt mixtures; $k_{1}, k_{2}$, and $k_{3}$ are laboratory regression coefficients; and $\beta_{f 1}$, $\beta_{f 2}$, and $\beta_{f 3}$ are local or global or mixture specific field calibration constants. 
For different asphalt materials or pavement locations, a different set of $k$-values and set of $\beta$-values are required. In some emerging mechanistic pavement design methods, mechanics aided experimental investigations take the place of the empirical model like Equation 2 to evaluate fatigue cracking. For example, Texas Mechanistic-Empirical Flexible Pavement Design System (TxME) utilizes the Paris' law with the stress intensity factor to predict the propagation of fatigue cracking. The values of $A$ and $n$ are obtained using the Overlay Tester (Zhou et al., 2010; Hu et al., 2014). Other examples are the Simplified Viscoelastic Continuum Damage (S-VECD) model (Underwood et al., 2012) originated at North Carolina State University and the Push-Pull Viscoelastic Continuum Damage (PP-VECD) software (Kutay, 2009) developed at Michigan State University. The S-VECD protocol is compatible with the asphalt mixture performance tester (AMPT) to perform cyclic fatigue tests under either controlledstress or controlled-strain mode. The PP-VECD relies on the so-called Push-Pull (compression-tension) fatigue tests conducted under controlled-strain mode. The major outputs of both S-VECD and PP-VECD include the damage characteristic curve and the number of cycles to failure, $N_{f}$. The damage characteristic curve is the kernel of the VECD theory, which refers to the pseudo stiffness $(C)$ versus the damage parameter $(S)$ relationship. In the S-VECD model, $N_{f}$ is derived from the damage evolution law, and its final expression contains the parameters in the $C$ versus-S relationship and the damage at failure, $S_{\text {failure. }}$ The magnitude of $N_{f}$ depends on how $S_{\text {failure }}$ is defined. In the PP-VECD software, $N_{f}$ is computed based on the criterion of $50 \%$ reduction of the dynamic modulus.

The examples above demonstrate the feasibility of incorporating mechanics-aided experimental investigations in asphalt pavement design. These applications have obvious advantages such as material assessment/ranking and more robust analysis and accurate prediction of fatigue life. However, there exist some shortcomings that need careful examinations and re-formulation. The problem associated with a fracture mechanics tool like Equation 1 is its appropriateness to a viscoelastic, viscoplastic, and viscofracturing material type like asphalt mixtures. By definition, $K$ is formulated under the linear elastic fracture mechanics and $J$ is under the elastic-plastic fracture mechanics, but the crack displacement and stress as well as the energy release rate of asphalt mixtures contain the time-dependent (i.e. viscoelastic) component. The 
viscoelastic displacement and energy dissipation must be separated from the cracking process when modeling the growth of cracks. This can be achieved by introducing the concept of elastic-viscoelastic correspondence principle (Schapery, 1984). This principle is also the foundation of the S-VECD and PPVECD in generating the damage characteristic curve. However, the way to define the fundamental material property (e.g., reference modulus) of this principle might not be appropriate in the S-VECD and PP-VECD models where the reference modulus was assigned as a unit pressure (i.e., $1 \mathrm{~Pa}$ ). In addition, the fracture mechanics and continuum damage mechanics tools mentioned above have a common feature: significant experimental investigations are needed in order to acquire the necessary fracture/damage parameters. This extended protocol makes them not as convenient as Equation 2 for pavement design.

Targeting these problems, this paper is intended to propose appropriate and convenient techniques to implement mechanics in asphalt pavement analysis and design in terms of fatigue cracking. The first technique aims at determining a rational and appropriate reference modulus for the use in both fracture mechanics and continuum damage mechanics models by making use of the widely used material property (i.e., dynamic modulus), which is detailed in the next section. The second technique discussed subsequently aims at making use of the dynamic modulus and mixture design information (e.g., air void content, aggregate gradation, binder content, etc.) to determine the fracture parameters and eventually allow the fatigue crack growth prediction without performing fatigue tests. Then several case studies are presented to illustrate how these techniques are applied in material assessment/ranking and pavement fatigue prediction. The last section summarizes the major contributions of this paper and the planned future work.

\section{Quasi-Elastic Simulation of Viscoelasticity}

The objective of this section is to propose the concept of "quasi-elastic simulation of viscoelasticity" to enable accurate viscoelastic-to-elastic conversion using readily available material properties for asphalt pavement design. The following topics will be addressed in turn:

1) Definition of quasi-elastic simulation;

2) Physical significance of quasi-elastic simulation; and 
3) Experimental validation of quasi-elastic simulation.

\subsection{Definition of Quasi-Elastic Simulation}

The concept of quasi-elastic simulation of viscoelasticity stems from the elasticviscoelastic correspondence principle (Schapery, 1984), which states that the solutions of a viscoelastic problem can be inferred from a reference elastic problem. Expressed using the constitutive equation, the viscoelastic stress and strain have the following relationship:

$$
\sigma_{v e}(t)=\int_{0}^{t} E(t-\tau) \frac{d \varepsilon(\tau)}{d \tau} d \tau
$$

where $\sigma_{v e}(t)$ is the viscoelastic stress corresponding to the strain history $\varepsilon(t)$; $t$ is the loading time; $\tau$ is any arbitrary time between 0 and $t$; and $E(t)$ is the relaxation modulus of the viscoelastic material. In the corresponding elastic reference, the constitutive equation becomes the relationship between the stress and the pseudo strain:

$$
\sigma_{v e}(t)=E_{R} \varepsilon_{R}
$$

where $\varepsilon_{R}$ is the pseudo strain; and $E_{R}$ is the reference modulus. In the S-VECD and PP-VECD models, $E_{R}$ is selected to be 1 . However, it is preferred to make the pseudo strain have physical significance. A good option is to assign the elastic modulus, or Young's modulus to the reference modulus (Zhang et al., 2012). The resulting pseudo strain is thus expressed as:

$$
\varepsilon_{R}=\varepsilon-\varepsilon^{v e}= \begin{cases}\varepsilon^{e} & \text { Undamaged state } \\ \varepsilon^{e}+\varepsilon^{d} & \text { Damaged state }\end{cases}
$$

where $\varepsilon^{v e}$ is the viscoelastic strain; $\varepsilon^{e}$ is the elastic strain; and $\varepsilon^{d}$ is the damage strain, which consists of the plastic strain, viscoplastic strain, and viscofracture strain. It can be seen that viscoelastic effects are removed from the material response in Equation 5. By definition, the elastic modulus is the ratio of the stress and strain that is instantaneous to this stress (i.e., elastic strain), namely it is time or frequency independent. As a result, when the elastic modulus is used as the reference modulus, the viscoelastic stress and resulting pseudo strain have a 
true elastic relationship that is irrelevant to the frequency of the loading. Such a simulation can be regarded as the elastic simulation of viscoelasticity.

In addition to the elastic modulus, for repeated loading another option is to use the dynamic modulus at the endurance limit as the reference modulus (Luo et al., 2013a; 2014). The endurance limit is the threshold between the undamaged and damaged states under repeated loading. Determining the dynamic modulus of asphalt mixtures at the endurance limit requires a series of tests at different loading levels and statistical analysis of measured material properties as detailed in Luo et al. (2013a; 2014). Note that the dynamic modulus at the endurance limit remains statistically the same as the load repetition increases. When this dynamic modulus is adopted as the reference modulus, it yields the same pseudo strain as that in Equation 5, but the difference is that the dynamic modulus is frequency dependent. Therefore, the viscoelastic stress is elastically related to the resulting pseudo strain at a specific frequency but not at others. For a repeated load with different frequencies, different dynamic moduli must be used to compute the corresponding pseudo strain for asphalt mixtures.

Compared to the elastic modulus, the dynamic modulus is more commonly used in asphalt pavement design to account for the frequency and temperature dependence of asphalt surface materials. Standard tests are available to measure the dynamic modulus under a haversine load (ASTM, 2003). In the latest mechanistic-empirical pavement design methods (e.g. MEPDG), the dynamic modulus is utilized in the multi-layer elastic analysis to determine the primary responses in asphalt pavements. However, a recent study (Underwood and Kim 2009) brings up a question about such a usage: the standard method to calculate the dynamic modulus actually characterizes the material response to a sinusoidal load rather than a haversine load. A haversine load can be decomposed into a sinusoidal loading portion and a constant loading portion. To correctly represent the material response to a haversine load in the multi-layer elastic analysis, Underwood and Kim (2009) proposed a combined compliance by the dynamic compliance and the creep compliance to characterize the relationship between the haversine stress amplitude and the resulting strain amplitude: 


$$
\varepsilon_{0}=\sigma_{0}\left[\frac{\left|D^{*}\right|_{f=\frac{1}{t_{p}}}+D\left(t=\frac{t_{p}}{2}\right)}{2}\right]
$$

where $\varepsilon_{0}$ is the strain amplitude; $\sigma_{0}$ is the stress amplitude of a haversine load; $\left|D^{*}\right|$ is the dynamic compliance; $f$ is the frequency of a load pulse; $t_{p}$ is the pulse time of a load; and $D(t)$ is the creep compliance. Based on Equation 6 , the appropriate compliance, or modulus, for the elastic analysis of asphalt surface materials should be the average of the dynamic response function at a frequency equal to $\frac{1}{t_{p}}$ and the time-dependent response function at a time equal to $\frac{t_{p}}{2}$, called representative elastic compliance or representative elastic modulus. The representative elastic modulus is originally intended to be used in the multi-layer elastic analysis for pavement design. It performs a similar function as the elastic modulus but depends on the loading frequency. If the representative elastic modulus can be used as the reference modulus to compute the pseudo strain, it has practical implications for making use of the prevalent material property in asphalt pavement design, and avoid extra testing efforts devoted to determine the endurance limit. The following section explores this application to see whether the resulting pseudo strain has the same physical significance as that in Equation 5. Using the representative elastic modulus to calculate the pseudo strain is called quasi-elastic simulation of viscoelasticity in this paper.

\subsection{Physical Significance of Quasi-Elastic Simulation}

The physical significance of the quasi-elastic simulation of viscoelasticity is discussed on the grounds of the theoretical derivation of the representative elastic modulus. The theoretical derivation is similar to the procedures in Underwood and Kim (2009), but a different loading scenario is used to conform with the loading condition in the experimental validation presented next. Moreover, a further discussion of the implications of the derivation is provided beyond the work in Underwood and Kim (2009). 
The derivation of the representative elastic modulus starts with a haversine-shaped strain pulse as shown in Figure 1. The mathematical form of the strain pulse is:

$$
\varepsilon_{h}(t)=\frac{\varepsilon_{h 0}}{2}\left[\sin \left(\omega t-\frac{\pi}{2}-\phi\right)+1\right]
$$

where $\varepsilon_{h}(t)$ is the haversine strain pulse; $\varepsilon_{h 0}$ is the strain amplitude of the haversine pulse; $\omega$ is the angular frequency; and $\phi$ is the phase angle. Equation 7 can be decomposed into two portions as:

$$
\varepsilon_{h}(t)=\varepsilon_{h 1}(t)+\varepsilon_{h 2}(t)
$$

in which:

$$
\begin{aligned}
\varepsilon_{h 1}(t) & =\frac{\varepsilon_{h 0}}{2} \sin \left(\omega t-\frac{\pi}{2}-\phi\right) \\
\varepsilon_{h 2}(t) & =\frac{\varepsilon_{h 0}}{2}
\end{aligned}
$$

Accordingly, the stress corresponding to $\varepsilon_{h}(t)$ at an equilibrium state after the initial transient period is the sum of the stress causing $\varepsilon_{h 1}(t)$ and that causing $\varepsilon_{h 2}(t)$, which is expressed as:

$$
\sigma_{h}(t)=\sigma_{h 1}(t)+\sigma_{h 2}(t)
$$

in which:

$$
\begin{aligned}
& \sigma_{h 1}(t)=\frac{\varepsilon_{h 0}}{2}\left|E^{*}\right| \sin \left(\omega t-\frac{\pi}{2}\right) \\
& \sigma_{h 2}(t)=\frac{\varepsilon_{h 0}}{2} E(t)
\end{aligned}
$$

where $\sigma_{h}(t)$ is the stress corresponding to the haversine strain pulse; $\sigma_{h 1}$ is the stress causing $\varepsilon_{h 1}(t) ; \sigma_{h 2}$ is the stress causing $\varepsilon_{h 2}(t) ;\left|E^{*}\right|$ is the dynamic modulus; and $E(t)$ is the relaxation modulus. Then the magnitude of $\sigma_{h}(t)$ is also the sum of two parts: 


$$
\sigma_{h 0}=\frac{\varepsilon_{h 0}}{2}\left|E^{*}\right|_{f=\frac{1}{t_{p}}}+\frac{\varepsilon_{h 0}}{2} E\left(t=\frac{t_{p}}{2}\right)
$$

The first part of Equation 14 is based on the MEPDG definition: the proper dynamic modulus or compliance to connect the stress and strain amplitudes is the one at a frequency equal to the inverse of the pulse time $t_{p}$ (ARA, 2004). The second part is based on the assumption stated in Underwood and Kim (2009): the stress amplitude occurs when the strain pulse reaches maximum at $\frac{t_{p}}{2}$. Equation 14 further reduces to:

$$
\frac{\sigma_{h 0}}{\varepsilon_{h 0}}=\frac{1}{2}\left[\left|E^{*}\right|_{f=\frac{1}{t_{p}}}+E\left(t=\frac{t_{p}}{2}\right)\right]
$$

Therefore, the representative elastic modulus, denoted $E_{r e}$ in this study, as the ratio of the stress amplitude to the strain amplitude, is calculated by:

$$
E_{r e}=\frac{1}{2}\left[\left|E^{*}\right|_{f=\frac{1}{t_{p}}}+E\left(t=\frac{t_{p}}{2}\right)\right]
$$

A further consideration is made herein for the assumption to obtain the second part of Equation 14 mentioned above. It implies that when deriving the representative elastic modulus the stress and strain pulses are in phase, namely an elastic relationship exists between the stress and strain. This implication, though not pointed out in Underwood and Kim (2009), is identical to the concept of the elastic-viscoelastic correspondence principle. As a result, the representative elastic modulus should be a promising candidate for the reference modulus. Next an experimental validation is conducted to further prove this inference. 


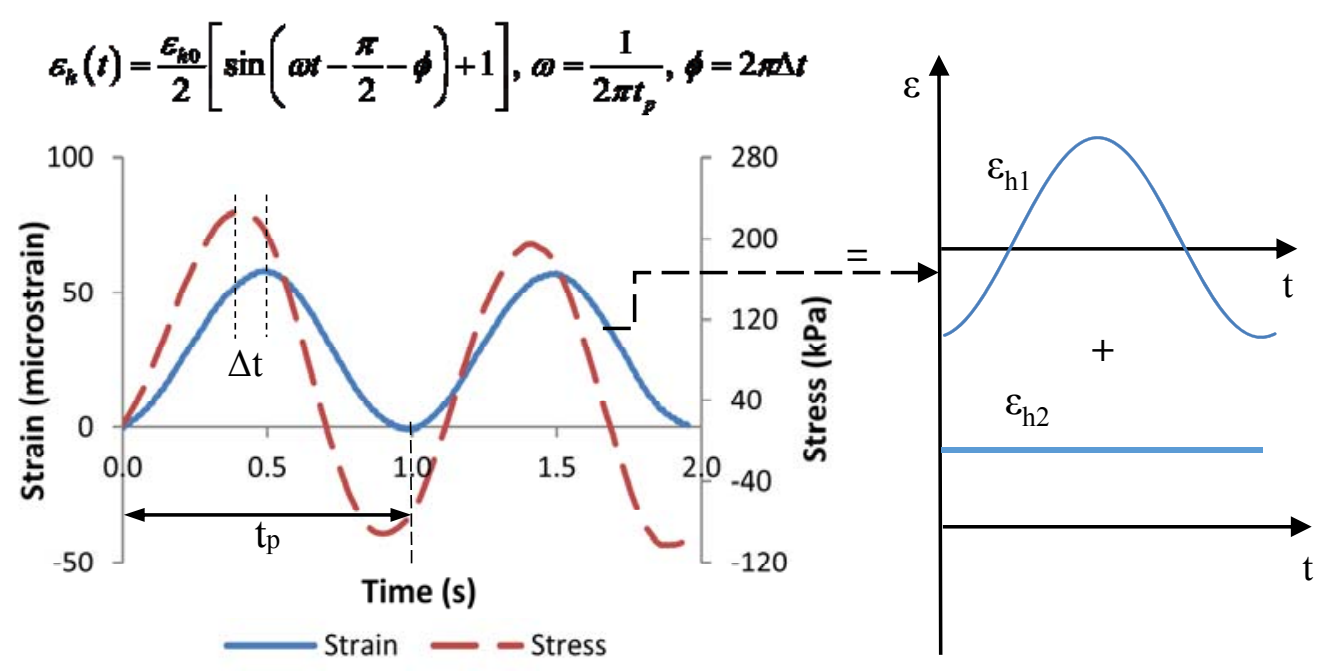

Figure 1. Decomposition of Typical Haversine-Shaped Strain Pulse

\subsection{Experimental Validation of Quasi-Elastic Simulation}

The experimental validation is performed by comparing the calculated representative elastic modulus by Equation 16 to the reference modulus measured from the test that resembles repeated traffic loading. It relies on the author's previous research results on determining endurance limits of asphalt mixtures (Luo et al., 2013a; 2014). The endurance limit is also called the critical nonlinear viscoelastic point, which serves as the reference state to quantify the damage. The dynamic modulus measured at this critical point, called the critical nonlinear viscoelastic property, successfully removes the viscoelastic effects when it is used to calculate the pseudo strain.

The experimental validation makes use of the authors' previous laboratory testing results, which contain two types of laboratory testing:

- Controlled-strain repeated direct tension test (RDT) (Luo et al., 2013a; 2013b); and

- Tensile creep and recovery test (Luo et al., 2013c).

The controlled-strain RDT tests are used to determine the critical nonlinear viscoelastic properties, denoted as $\left|E_{N L V E}^{*}\right|$, of tested asphalt specimens. They are conducted with 200 load cycles at a frequency of $1 \mathrm{~Hz}$ using the Material Test System (MTS) at $20^{\circ} \mathrm{C}$. The value of $\left|E_{N L V E}^{*}\right|$ is calculated for representative load cycles $\left(1^{\text {st }}-10^{\text {th }}, 50^{\text {th }}-59^{\text {th }}, 100-109^{\text {th }}, 150^{\text {th }}-159^{\text {th }}\right.$, and $\left.190^{\text {th }}-199^{\text {th }}\right)$ and the average 
of these cycles is used as the final result. The test setup, procedures and analysis methods were elaborated in the references above, so they are not repeated herein. The tensile creep and recovery tests are used to calculate the representative elastic moduli of the replicate asphalt specimens. They are performed using the MTS with a loading time of $60 \mathrm{~s}$ and recovery time of $120 \mathrm{~s}$ at three temperatures: $10^{\circ} \mathrm{C}$, $20^{\circ} \mathrm{C}$, and $30^{\circ} \mathrm{C}$. The test setup was detailed in the reference above, so is not repeated here. Only the analysis method to obtain the representative elastic modulus is given as follows:

1) Calculate the relaxation modulus of each tested specimen at $10^{\circ} \mathrm{C}, 20^{\circ} \mathrm{C}$, and $30^{\circ} \mathrm{C}$, respectively, by the Laplace transform of the creep compliance measured from the test, the same method as used in Zhang et al. (2012);

2) Construct the relaxation modulus master curve at the reference temperature of $20^{\circ} \mathrm{C}$ using the sigmoidal model suggested in the 2002 MEPDG (ARA, 2004):

$$
\log E\left(t_{r}\right)=c_{1}+\frac{c_{2}}{1+e^{c_{3}+c_{4} \log t_{r}}}
$$

where $t_{r}$ is the reduced time of loading at the reference temperature; and $c_{1}, c_{2}, c_{3}$, and $c_{4}$ are fitting parameters.

3) Convert the relaxation modulus master curve to the dynamic modulus by the following technique:

a. Assume a Prony series form of the relaxation modulus as below and determine the Prony series' coefficients by fitting the Equation 18 to the master curve of the relaxation modulus constructed in step 2:

$$
E(t)=E_{\infty}+\sum_{j=1}^{M} E_{j} e^{-\frac{t}{\kappa_{j}}}
$$

where $E_{\infty}$ is the long term relaxation modulus; $E_{j}$ are the relaxation modulus coefficients; and $\kappa_{j}$ are the relaxation times.

b. Compute the dynamic modulus by (Findley et al. 1989): 


$$
\left|E^{*}(\omega)\right|=\sqrt{\left(E_{\infty}+\sum_{j=1}^{M} \frac{\omega^{2} \kappa_{j}^{2} E_{j}}{1+\omega^{2} \kappa_{j}^{2}}\right)^{2}+\left(\sum_{j=1}^{M} \frac{\omega \kappa_{j} E_{j}}{1+\omega^{2} \kappa_{j}^{2}}\right)^{2}}
$$

With respect to the accuracy of the procedures above, efforts have been devoted to experimentally confirm that the dynamic modulus master curve converted from the creep test matches well with that measured from the dynamic modulus test.

The materials used in the experimental validation are laboratory-mixedlaboratory-compacted hot asphalt mixtures, including two types of asphalt binder and one type of aggregate. The asphalt binders are designated "NuStar" with PG 67-22 from New Jersey and "Valero" with PG 64-16 from California. The aggregate is the Hanson limestone from New Braunfels, Texas. The mixtures are fabricated to cylindrical specimens with dimensions of $102 \mathrm{~mm}$ in diameter and $152 \mathrm{~mm}$ high. In order to produce asphalt mixtures with different material properties and behaviors, two air void contents (4-5\% and 7-8\%) and three aging periods ( 0,3 months, and 6 months) are selected during the mixture design. Thus, there are 12 types of asphalt mixtures, each type with 3 replicate specimens.

All of the twelve types of asphalt mixtures are subjected to the two kinds of tests mentioned above, and the results are given in Table 1. Under "Mixture Type" of Table 1, the number " $4 \%$ " or " $7 \%$ " represents the air void content; the number of "0", "3", or "6" represents the aging period. For example, "NuStar, $7 \%, 6$ " means that the asphalt binder is NuStar, the air void content is $7 \%$, and the aging period is 6 months. In the controlled-strain RDT test, the dynamic modulus at the endurance limit, i.e. $\left|E_{N L V E}^{*}\right|$, is measured for each mixture type. In the tensile creep and recovery test, the value of $E\left(t=\frac{t_{p}}{2}\right)$ (where $\left.t_{p}=1 \mathrm{~s}\right)$ is obtained from the relaxation modulus master curve. Figure 2 shows two example master curves of the tested asphalt specimens. In the legend of Figure 2 as well as Figure 4 below, the word "Test" means the experimental data; "Shifted" indicates the data corresponding to the reduced time after introducing time-temperature shift factor. For example, " $30^{\circ} \mathrm{C}$-Test_NuStar, $4 \%, 6$ " in Figure 2 is the data measured at $30^{\circ} \mathrm{C}$ for mixture type NuStar, $4 \%, 6$ listed in Table 1 . The value of $\left|E^{*}\right|_{f=\frac{1}{t_{p}}}$ is calculated by Equation 19 (where $\omega=2 \pi f$ and $f=1 \mathrm{~Hz}$ ). With 
known $E\left(t=\frac{t_{p}}{2}\right)$ and $\left|E^{*}\right|_{f=\frac{1}{t_{p}}}, E_{r e}$ is determined by Equation 16. Plot $\left|E_{N L V E}^{*}\right|$ versus $E_{r e}$ in Figure 3 and fit the data with a linear function. It proves that the critical nonlinear viscoelastic property is statistically equal to the representative elastic modulus. Therefore, when assigning the representative elastic modulus to the reference modulus, it yields the same result as using the critical nonlinear viscoelastic property to compute the pseudo strain. In other words, the quasi-elastic simulation removes the viscoelastic strain and produces the same pseudo strain as shown in Equation 5.

Table 1. Laboratory Test Parameters and Results for Validation of Quasi-Elastic Simulation

\begin{tabular}{|c|c|c|c|c|}
\hline \multicolumn{5}{|c|}{ Controlled-Strain RDT Test } \\
\hline $\begin{array}{c}\text { Test } \\
\text { Parameters }\end{array}$ & \multicolumn{4}{|c|}{$f=1 \mathrm{~Hz} ; t_{p}=1 \mathrm{~s} ; \quad \omega=6.28 \mathrm{rad} / \mathrm{s} ; \quad$ temperature $=20^{\circ} \mathrm{C}$} \\
\hline \multirow{7}{*}{$\begin{array}{l}\text { Test } \\
\text { Results }\end{array}$} & Mixture Type & $\begin{array}{l}\left|E_{N L V E}^{*}\right| \\
(\mathrm{MPa})\end{array}$ & Mixture Type & $\begin{array}{l}\left|E_{N L V E}^{*}\right| \\
(\mathrm{MPa})\end{array}$ \\
\hline & NuStar, $4 \%, 0$ & 5078 & Valero, $4 \%, 0$ & 7774 \\
\hline & NuStar, $7 \%, 0$ & 4519 & Valero, $7 \%, 0$ & 5320 \\
\hline & NuStar, $4 \%, 3$ & 7579 & Valero, $4 \%, 3$ & 10683 \\
\hline & NuStar, $7 \%, 3$ & 5055 & Valero, $7 \%, 3$ & 7823 \\
\hline & NuStar, $4 \%, 6$ & 10017 & Valero, $4 \%, 6$ & 12483 \\
\hline & NuStar, $7 \%, 6$ & 7432 & Valero, $7 \%, 6$ & 9044 \\
\hline \multicolumn{5}{|c|}{ Tensile Creep and Recovery Test } \\
\hline $\begin{array}{c}\text { Test } \\
\text { Parameters }\end{array}$ & \multicolumn{4}{|c|}{$\begin{array}{c}\text { Loading time }=60 \mathrm{~s} ; \text { recovery time }=120 \mathrm{~s} ; \quad \text { temperature }=10, \\
20,30^{\circ} \mathrm{C}\end{array}$} \\
\hline \multirow{13}{*}{$\begin{array}{c}\text { Test } \\
\text { Results }\end{array}$} & Mixture Type & $\begin{array}{c}E\left(t=\frac{t_{p}}{2}\right. \\
(\mathrm{MPa})\end{array}$ & $\begin{array}{r}\left|E^{*}\right|_{f=\frac{1}{t_{p}}} \\
(\mathrm{MPa})\end{array}$ & $E_{r e}(\mathrm{MPa})$ \\
\hline & NuStar, 4\%, 0 & 4199 & 7030 & 5614 \\
\hline & NuStar, $7 \%, 0$ & 2963 & 5120 & 4041 \\
\hline & NuStar, $4 \%, 3$ & 5622 & 9740 & 7681 \\
\hline & NuStar, $7 \%, 3$ & 3554 & 5624 & 4589 \\
\hline & NuStar, $4 \%, 6$ & 7725 & 11048 & 9387 \\
\hline & NuStar, $7 \%, 6$ & 5269 & 8214 & 6742 \\
\hline & Valero, $4 \%, 0$ & 6501 & 10853 & 8677 \\
\hline & Valero, $7 \%, 0$ & 3691 & 6326 & 5008 \\
\hline & Valero, $4 \%, 3$ & 8425 & 12013 & 10219 \\
\hline & Valero, $7 \%, 3$ & 5801 & 9300 & 7550 \\
\hline & Valero, $4 \%, 6$ & 9690 & 13831 & 11761 \\
\hline & Valero, $7 \%, 6$ & 7673 & 11287 & 9480 \\
\hline
\end{tabular}




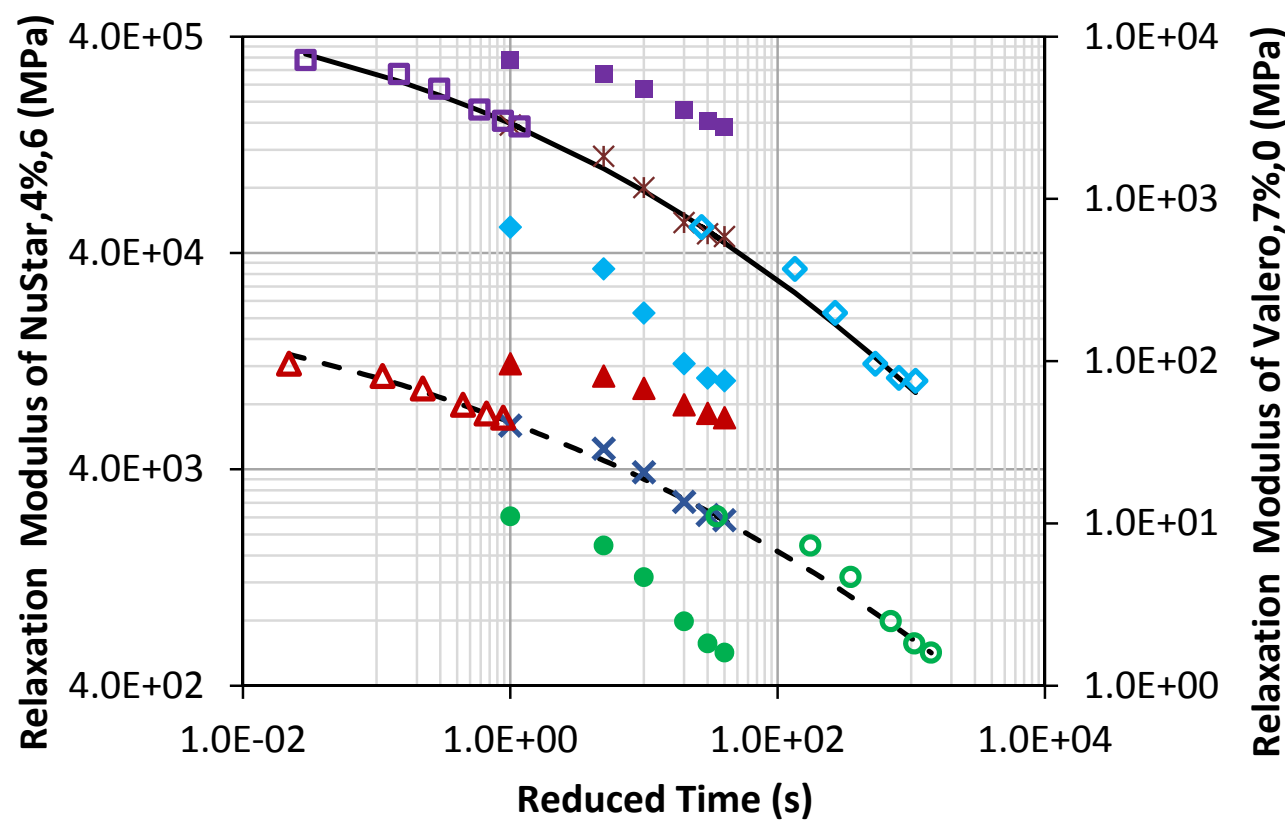

- $30^{\circ} \mathrm{C}$-Test_NuStar, $4 \%, 6$

- $10^{\circ} \mathrm{C}$-Test_NuStar,4\%,6

$\Delta \quad 10^{\circ} \mathrm{C}$-Shifted_NuStar,4\%,6

* $20^{\circ} \mathrm{C}$-Test_Valero, $7 \%, 0$

․ $10^{\circ} \mathrm{C}$-Shifted_Valero, $7 \%, 0$

- $10^{\circ} \mathrm{C}$-Test_Valero, $7 \%, 0$

E(t) Master Curve_Valero,7\%,0

Figure 2. Examples of Relaxation Modulus Master Curves at Reference Temperature $20^{\circ} \mathrm{C}$

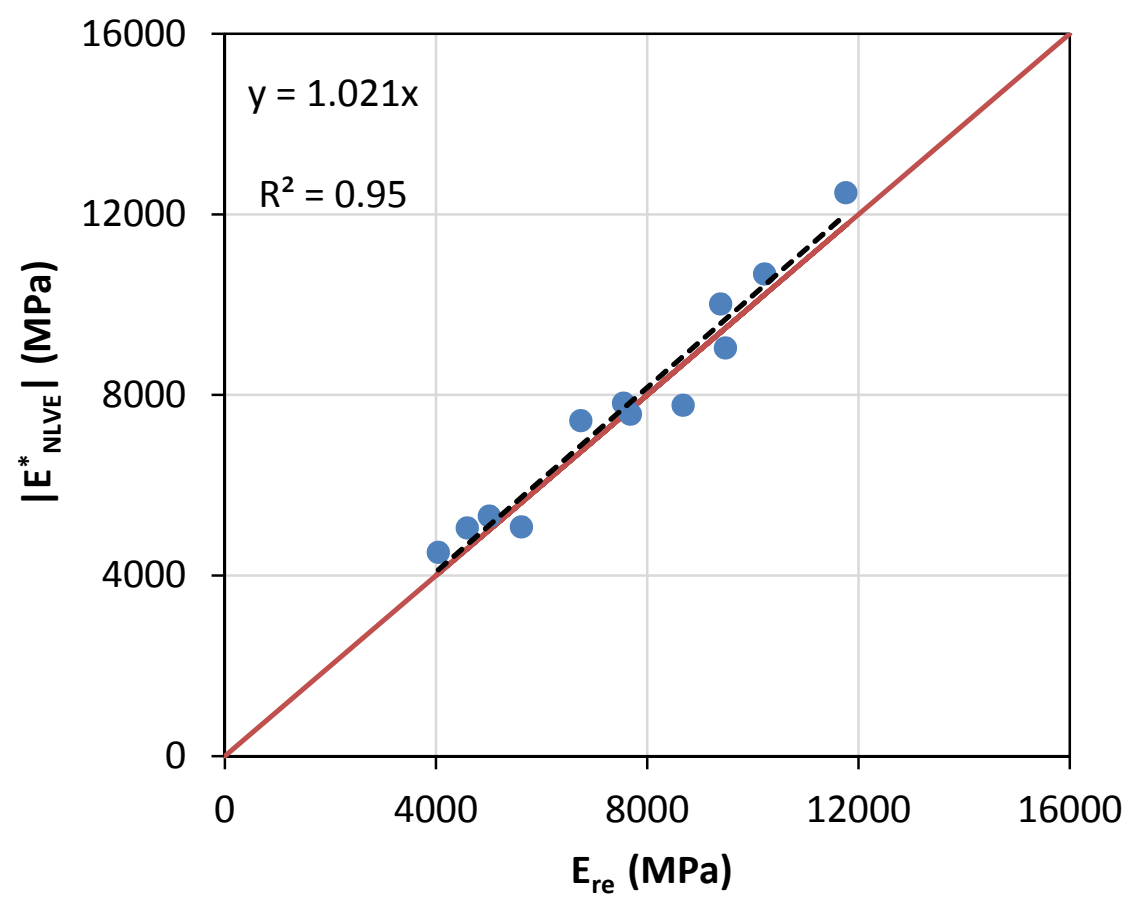

_Equivalence line ----- Linear (12 types of mixtures)

Figure 3. Comparison of Critical Nonlinear Viscoelastic Properties and Representative Elastic Moduli 
The quasi-elastic simulation is easily fitted to the continuum damage mechanics tools like S-VECD and PP-VECD, in which the dynamic modulus is a required input. When it is used in the fracture mechanics tool, it allows a convenient conversion from the viscoelastic model to the elastic model. For example, the Paris' law based on viscoelastic J-integral can be converted into the Paris' law based on an "elastic" J-integral. By doing so, the viscoelastic energy dissipation is removed and the crack growth rate is precisely characterized by the energy release rate directly responsible for cracking for an asphalt mixture.

\section{Simplification of Fatigue Cracking Prediction}

The objective of this section is to propose a simplified mechanics-aided method to predict fatigue cracking in asphalt pavements with or without performing fatigue tests. The mechanics tool selected for simplification is the Paris' law since its fracture coefficients are material-specific and can be estimated using simple performance-related material properties. The following topics will be discussed:

1) Introduction of modified Paris' law with the application of quasi-elastic simulation; and

2) Estimation of modified Paris' law coefficients using performance-related material properties.

\subsection{Modified Paris' Law with Application of Quasi-Elastic Simulation}

The modified Paris' law was early proposed in one of the authors' studies as (Luo et al., 2013d):

$$
\frac{d \phi}{d N}=A^{\prime}\left(J_{R}\right)^{n^{\prime}}
$$

where $\phi$ is the damage density; $J_{R}$ is the pseudo J-integral; and $A^{\prime}$ and $n^{\prime}$ are modified Paris' law parameters associated with the evolution of the damage density. The damage density replaces the crack length to account for the fact that there are a multitude of cracks in asphalt mixtures in the early stage of fatigue cracking. The cracking history of asphalt mixtures usually has three stages from the beginning of fracture to failure: 1) the formative phase, in which more and more microcracks are generated when cracking is initiated;2) the coalescent phase, in which microcracks merge and coalesce to form larger cracks; and 3) the 
unitary phase, in which a few macrocracks are formed to dominate the failure of the material (Luo et al. 2014). The first two stages are modeled using Equation 20. The unitary phase is modeled by replacing the damage density by the crack length:

$$
\frac{d c}{d N}=A^{\prime}\left(J_{R}\right)^{n^{\prime}}
$$

The pseudo J-integral is defined by:

$$
J_{R}=\frac{\partial \mathrm{DPW}}{\partial(\text { crack surface area })}
$$

where "DPW" stands for the dissipated pseudo work, which is calculated by:

$$
\mathrm{DPW}=\int_{V} \int_{t_{1}}^{t_{2}} \sigma(t) \frac{d \varepsilon_{R}(t)}{d t} d t d V
$$

in which $\sigma(t)$ is the stress applied to the material; $\varepsilon_{R}$ is the pseudo strain; $t_{1}$ and $t_{2}$ is the start and end times of a loading period, and $V$ is the volume of the material. For a complete loading and unloading cycle, the amount of DPW is manifested by the area enclosed in a hysteresis loop of the load versus the pseudo displacement. The DPW represents the work consumed due to damage formation in an asphalt material. Thus the physical significance of $J_{R}$ is the pseudo energy release rate that quantifies the rate of the change of the energy solely responsible for crack growth. The "crack surface area" refers to the area of the crack surfaces on a cross section of the material, which is calculated by:

$$
\text { Crack surface area }= \begin{cases}2 \phi S & \text { formative and coalescent phases } \\ 2 c w & \text { unitary phase }\end{cases}
$$

in which the factor " 2 " is needed because each crack has two surfaces; $S$ is the cross sectional area of the material; and $w$ is the thickness of the material. In the unitary phase a through-thickness crack is assumed in Equation 24.

With the application of the quasi-elastic simulation, the calculation of $J_{R}$ becomes fairly simple. One way is to compute $\varepsilon_{R}$ by Equations 3 and 4 using the reference modulus given by Equation 16; then calculate $J_{R}$ through 
Equations 22 to 24 . Another option is to convert $K$ to $J_{R}$ by the following relationship (Anderson 1995):

$$
J_{R}=\frac{1-v^{2}}{E_{R}}\left(K_{I}^{2}+K_{I I}^{2}\right)+\frac{1+v}{E_{R}} K_{I I I}^{2}
$$

in which $E_{R}$ is determined as the representative elastic modulus given by Equation 16; $v$ is the Poisson's ratio; $K_{I}$ is the Mode I (opening) stress intensity factor; $K_{I I}$ is the Mode II (in-plane shear) stress intensity factor; and $K_{I I I}$ is the Mode III (out of plane shear) stress intensity factor.

Accordingly, the application of the modified Paris' law to quantify the amount of cracking also has two options. One way is to first simulate the change of the DPW with the increase of the number of load cycles by a power function as:

$$
\mathrm{DPW}=a N^{b}
$$

in which $a$ and $b$ are regression coefficients of the curve of the DPW versus $N$. Then substitute Equations 24 and 26 into Equations 20 and 21 and perform a series of manipulations, which give the following two similar expressions:

$$
\begin{aligned}
& \phi=A^{\prime \frac{1}{n^{\prime}+1}}\left(\frac{a b}{2 S}\right)^{\frac{n^{\prime}}{n^{\prime}+1}}\left(\frac{n^{\prime}+1}{b n^{\prime}+1}\right) N^{\frac{b n^{\prime}+1}{n^{\prime}+1}}+\phi_{0} \\
& c=A^{\prime \frac{1}{n^{\prime}+1}}\left(\frac{a b}{2 w}\right)^{\frac{n^{\prime}}{n^{\prime}+1}}\left(\frac{n^{\prime}+1}{b n^{\prime}+1}\right) N^{\frac{b n^{\prime}+1}{n^{\prime}+1}}+c_{0}
\end{aligned}
$$

where $\phi_{0}$ is the initial damage density; and $c_{0}$ is the initial crack size. Detailed manipulations can be found in Luo et al. (2013d) and are not repeated here. Another option is to compute $J_{R}$ by Equation 25; then substitute $J_{R}$ into Equations 20 and 21 to determine $\phi$ or $c$ through an iteration technique, which is elaborated later in the case study. No matter which option is selected, the fracture coefficients $A^{\prime}$ and $n^{\prime}$ are required. The routine methods to determine $A^{\prime}$ and $n^{\prime}$ are through cyclic load tests. In this study, a simplified approach is proposed to estimate them using performance-related material properties, which is presented next. 


\subsection{Estimation of Fracture Coefficients by Performance-Related Properties}

The primary consideration of estimating the modified Paris' law coefficients by performance-related properties is to allow fatigue prediction when experimental investigations are not available. It can also act as a quick and cost-effective alternative to check fatigue resistance of asphalt mixtures. To ensure the accuracy and reliability of the estimation, the following steps are undertaken:

- Step 1. Collect test data and determine $A^{\prime}$ and $n^{\prime}$;

- Step 2. Select performance-related material properties;

- Step 3. Develop prediction models of $A^{\prime}$ and $n^{\prime}$ through selected performance-related material properties.

\section{Step 1. Collect test data and determine $A^{\prime}$ and $n^{\prime}$}

As the first step, collecting sufficient accurate data of $A^{\prime}$ and $n^{\prime}$ is of prime importance. Three data sources are identified for this purpose:

- Jacobs (1995)'s dynamic uniaxial tensile test data;

- Luo et al. (2013d)'s controlled-strain RDT test data; and

- Gu et al. (2014)'s overlay test data.

Jacobs (1995) used dynamic uniaxial tensile tests to determine fracture characteristics of different asphalt mixtures. During the tests, the crack opening displacement (COD) measurements were carried out to provide information about the complete fracture process from microcracks to macrocracks. Then, this information was utilized to determine $A$ and $n$ in Equation 1 with the stress intensity factor $K_{I}$, and the results are documented in Appendix 7A of Jacobs (1995). The values of $A$ and $n$ in Appendix 7A must be converted to that of $A^{\prime}$ and $n^{\prime}$ first. The conversion needs to consider the unit of the variables as follows:

$$
\frac{d c}{d N}=A\left(\frac{K_{I}}{1 \cdot \mathrm{MPa} \sqrt{\mathrm{mm}}}\right)^{n}=A^{\prime}\left(\frac{J_{R}}{1 \cdot N / m}\right)^{n^{\prime}}
$$

Substituting Equation 25 into 29 gives: 


$$
A\left(K_{I}\right)^{n}\left(\frac{1}{\operatorname{MPa} \sqrt{\mathrm{mm}}}\right)^{n}=A^{\prime}\left(K_{I}\right)^{2 n^{\prime}}\left(\frac{1-v^{2}}{E_{R}}\right)^{n^{\prime}}\left(\frac{1}{N / m}\right)^{n^{\prime}}
$$

Compare the left and right sides of Equation 30, which yields:

$$
\begin{aligned}
& n^{\prime}=\frac{n}{2} \\
& A^{\prime}=A\left(\frac{E_{R}}{1-v^{2}} \frac{1}{\mathrm{MPa} \cdot 10^{3}}\right)^{\frac{n}{2}}
\end{aligned}
$$

The reference modulus in Equation 32 is computed as $E_{r e}$ by Equation 16. The Poisson's ratio is assigned the same value of 0.35 as in Jacobs (1995). The dynamic modulus test results at different frequencies and temperatures in Appendix 6A of Jacobs (1995) are used to determine $E_{r e}$. The procedure is similar to that of utilizing the tensile creep and recovery test to compute $E_{r e}$ presented above, which is:

1) Construct the dynamic modulus master curve at the reference temperature of $25^{\circ} \mathrm{C}$ using the sigmoidal model similar to Equation 17.

2) Convert the dynamic modulus master curve to the relaxation modulus using the same forms in Equations 18 and 19.

Figure 4 shows an example of the dynamic modulus master curve produced by the data in Appendix 6A of Jacobs (1995). 


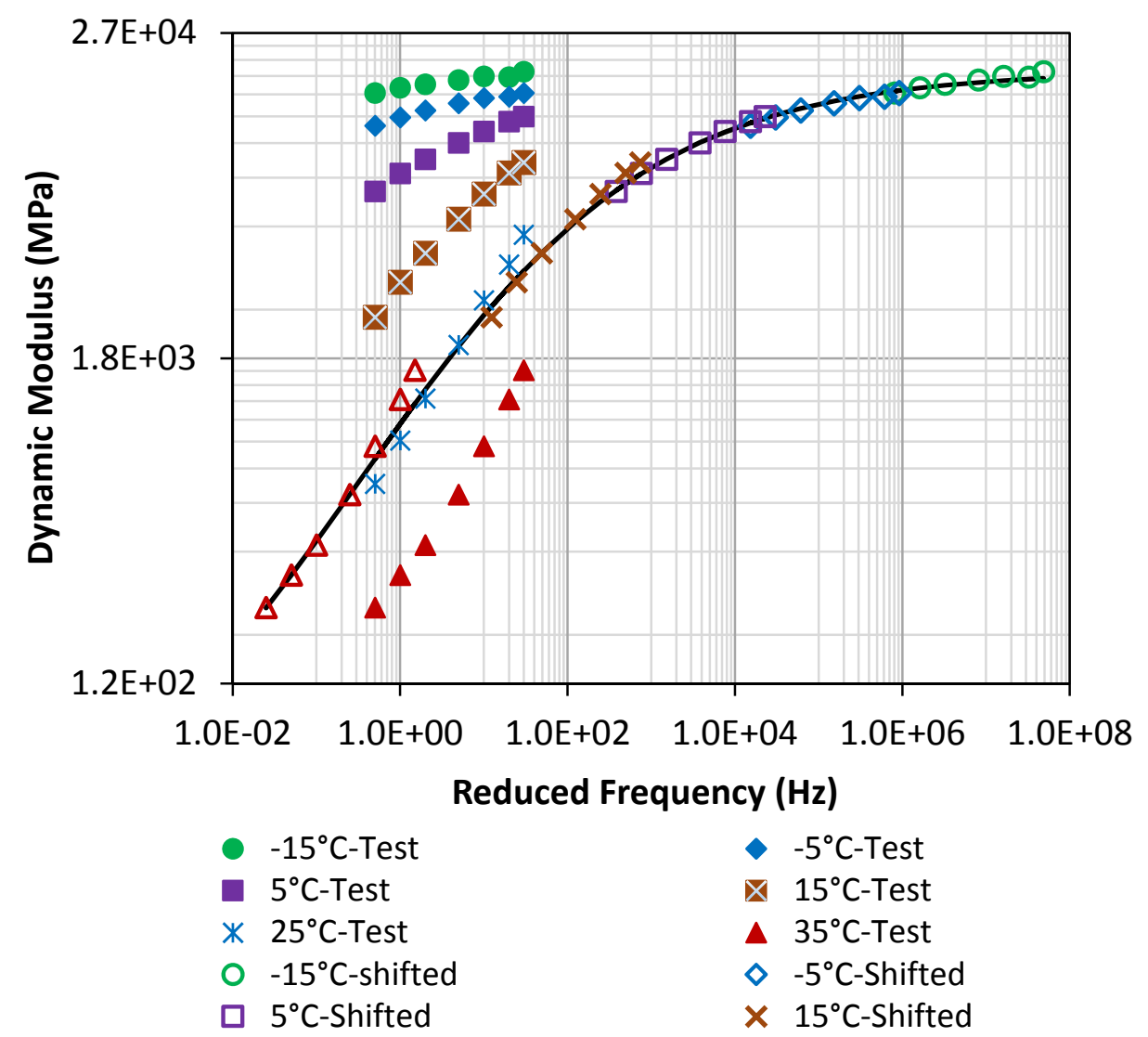

Figure 4. Example of Dynamic Modulus Master Curve at Reference Temperature $25^{\circ} \mathrm{C}$

The materials used in Jacobs (1995) to obtain $A$ and $n$ include five types of asphalt mixtures: two dense asphalt mixtures, denoted as "DAC8" and "DAC16"; one dense asphalt mixture with a modified binder, "DACmod"; one stone mastic asphalt mixture, "SMA"; and one sand asphalt mixture, "SA", which are shown in Table 2. For each mixture type, several replicate specimens are fabricated and subjected to the dynamic tests under the frequencies and temperatures shown in Table 2. For example, under Test 1a of DACmod, three specimens are tested at a frequency of $8 \mathrm{~Hz}$ at $15^{\circ} \mathrm{C}$. Such details can be found in Appendix 7A of Jacobs (1995). There are a total of 181 data points in Appendix 7A. Under some circumstances, a relatively high variability exists among the replicates that are tested under the same condition. To reduce the data variance, the average of the replicates is used for the same test condition. Thus Jacobs (1995)'s data reduce from 181 to 57 different pairs. In addition, the representative elastic modulus for a specific pair of frequency and temperature is computed following the procedure above and given in Table 2. With known $E_{R}, n^{\prime}$ and $A^{\prime}$ of Jacobs (1995)'s materials are determined by Equations 31 and 32. 
Table 2. Material Information and Calculated Representative Elastic Modulus of Jacob (1995)'s Test Data for Determining Fracture Coefficients

\begin{tabular}{|c|c|c|c|c|c|c|}
\hline $\begin{array}{l}\text { Mixture } \\
\text { Type }\end{array}$ & Test & $\begin{array}{c}\text { Temperatur } \\
\text { e }\left({ }^{\circ} \mathrm{C}\right)\end{array}$ & $\begin{array}{c}\text { Frequency } \\
\text { (Hz) }\end{array}$ & $\begin{array}{c}E_{r e} \\
\text { (MPa) }\end{array}$ & $\begin{array}{c}\text { Air } \\
\text { Void } \\
\text { Content } \\
(\%) \\
\end{array}$ & $\begin{array}{c}\text { Binder } \\
\text { Content } \\
(\%)\end{array}$ \\
\hline \multirow{6}{*}{ DACmod } & $\begin{array}{l}1 \mathrm{a}, 3 \mathrm{a}, \\
3 \mathrm{~b}, 3 \mathrm{c}, \\
4 \mathrm{a}, 4 \mathrm{~b}\end{array}$ & 15 & 8 & 3098 & \multirow{6}{*}{2.0} & \multirow{6}{*}{6.0} \\
\hline & $1 \mathrm{~b}$ & 25 & 8 & 1714 & & \\
\hline & $1 \mathrm{c}$ & 5 & 8 & 5190 & & \\
\hline & $2 a$ & 15 & 2 & 2178 & & \\
\hline & $2 b$ & 15 & 4 & 2616 & & \\
\hline & $2 c$ & 15 & 16 & 3609 & & \\
\hline \multirow{6}{*}{ SMA } & $\begin{array}{l}1 \mathrm{a}, 3 \mathrm{a}, \\
3 \mathrm{~b}, 3 \mathrm{c}, \\
4 \mathrm{a}, 4 \mathrm{~b}\end{array}$ & 15 & 8 & 3661 & \multirow{6}{*}{3.0} & \multirow{6}{*}{7.0} \\
\hline & $1 \mathrm{~b}$ & 25 & 8 & 1708 & & \\
\hline & $1 \mathrm{c}$ & 5 & 8 & 6286 & & \\
\hline & $2 a$ & 15 & 2 & 2446 & & \\
\hline & $2 b$ & 15 & 4 & 3027 & & \\
\hline & $2 \mathrm{c}$ & 15 & 16 & 4334 & & \\
\hline \multirow{6}{*}{ SA } & $\begin{array}{r}1 \mathrm{a}, 3 \mathrm{a}, 3 \mathrm{~b} \\
3 \mathrm{c}, 4 \mathrm{a}\end{array}$ & 15 & 8 & 3414 & \multirow{6}{*}{8.3} & \multirow{6}{*}{10.0} \\
\hline & $1 \mathrm{~b}$ & 25 & 8 & 2116 & & \\
\hline & $1 \mathrm{c}$ & 5 & 8 & 4873 & & \\
\hline & $2 a$ & 15 & 2 & 2167 & & \\
\hline & $2 b$ & 15 & 4 & 2766 & & \\
\hline & $2 \mathrm{c}$ & 15 & 16 & 4082 & & \\
\hline \multirow[t]{4}{*}{ DAC8 } & $\begin{array}{l}1 \mathrm{a}, 3 \mathrm{a}, \\
3 \mathrm{~b}, 3 \mathrm{c} \\
4 \mathrm{a}, 4 \mathrm{~b}, \\
4 \mathrm{c}, 5 \mathrm{a}, \\
5 \mathrm{~b}, 5 \mathrm{c}\end{array}$ & 15 & 8 & 3344 & \multirow[t]{4}{*}{7.9} & \multirow[t]{4}{*}{6.8} \\
\hline & $1 b$ & 25 & 8 & 1589 & & \\
\hline & $1 \mathrm{c}$ & 5 & 8 & 5920 & & \\
\hline & $2 a$ & 15 & 2 & 2022 & & \\
\hline \multirow{12}{*}{ DAC16 } & $1 \mathrm{a}$ & 15 & 8 & 3177 & \multirow{3}{*}{1.1} & \multirow{5}{*}{6.2} \\
\hline & $1 \mathrm{~b}$ & 25 & 8 & 1444 & & \\
\hline & $1 \mathrm{c}$ & 5 & 8 & 5522 & & \\
\hline & $2 a$ & \multirow{9}{*}{15} & \multirow{9}{*}{8} & \multirow{9}{*}{3177} & 5.1 & \\
\hline & $2 b$ & & & & 1.6 & \\
\hline & $3 a$ & & & & 1.5 & 5.7 \\
\hline & $3 b$ & & & & 0.8 & 5.95 \\
\hline & $3 c$ & & & & 1.3 & 6.7 \\
\hline & $4 a$ & & & & 2.0 & \multirow{4}{*}{6.2} \\
\hline & $4 \mathrm{~b}$ & & & & 2.3 & \\
\hline & $5 a$ & & & & 0.3 & \\
\hline & $5 b$ & & & & 0.8 & \\
\hline
\end{tabular}


Luo et al. (2013d) used controlled-strain RDT test to determine $A^{\prime}$ and $n^{\prime}$ of a variety of asphalt mixtures. The load and displacement of the tested specimen are measured, and then an Energy-Based Mechanistic (EBM) approach is utilized to analyze the stress and strain data. A primary outcome of the EBM approach is the evolution curve of the damage density. This curve is used to determine $A^{\prime}$ and $n^{\prime}$ of the modified Paris' law in Equation 20. Detailed procedures are not repeated; only the results of $A^{\prime}$ and $n^{\prime}$ are presented herein. It is worth mentioning that the method to calculate the pseudo J-integral is improved as shown in Equation 22. Accordingly the values of $A^{\prime}$ and $n^{\prime}$ are recalculated in this study using the same test data in Luo et al. (2013d). The materials in Luo et al. (2013d) include the 12 types of asphalt mixtures illustrated in Table 1 and another 8 types, totally 20 mixture types. These additional eight types of mixtures are made of two asphalt binders: AAD and AAM from the Strategic Highway Research Program Materials Reference Library (Jones, 1993) and one aggregate type: Texas limestone from San Marcos, Texas. In the mixture design, two air void contents (4\% and 7\%) and two aging periods ( 0 and 6 months) are chosen. As a result, there are 20 data points collected from Luo et al. (2013d).

Gu et al. (2014) utilized the overlay test to study fracture properties of both hot mix asphalt (HMA) and warm mix asphalt (WMA). The stress and strain data are obtained from the measured load and displacement of the tested specimen. Then a combined analytical and numerical approach is employed to calculate $A^{\prime}$ and $n^{\prime}$ in Equation 21. More details can be referred to Gu et al. (2014). The materials are laboratory-mixed-laboratory-compacted asphalt mixtures, including one type of control HMA and two types of WMA mixtures. The two WMA mixtures are produced respectively by the Evotherm DAT and water-based foaming technologies. The target air void content is $7 \%$. For each mixture type, four replicate specimens are prepared and tested. Thus, there are 12 data points collected from Gu et al. (2014).

From the three studies above, there are altogether 89 different pairs of $A^{\prime}$ and $n^{\prime}$. The plot of $-\log \left(A^{\prime}\right)$ versus $n^{\prime}$ is shown in Figure 5. When a straight line is fitted to the data in Figure 5, the R-squared of the linear function is 0.892. 
This suggests a strong correlation between the modified Paris' law coefficients. Once one of them is known, the other coefficient can be estimated by:

$$
A^{\prime}=10^{-\left(1.246 n^{\prime}+3.615\right)}
$$

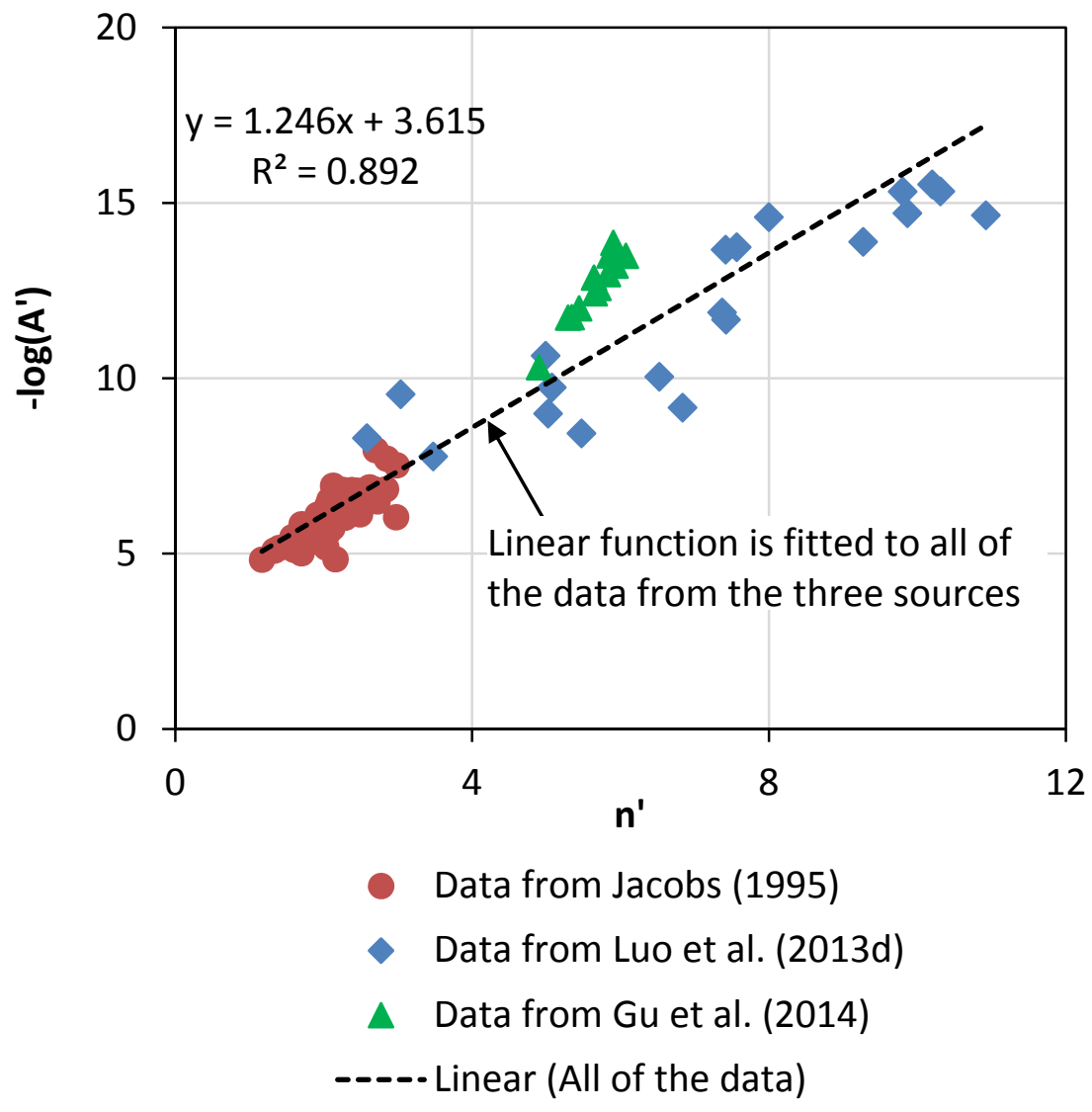

Figure 5. Relationship between Fracture Coefficients $A^{\prime}$ and n'

\section{Step 2. Select performance-related material properties}

The material properties selected to estimate $A^{\prime}$ and $n^{\prime}$ need to be directly related to the cracking performance of asphalt materials. More importantly, these properties should be readily available for most asphalt pavement design. After extensive screening and evaluation, the following material properties are identified:

- Relaxation modulus: a simple model is proposed here for the relaxation modulus in order to reduce the variables in the prediction:

$$
E(t)=E_{1} t^{-m}
$$

where $E(t)$ is the relaxation modulus of asphalt mixtures; and $E_{1}$ and $m$ are the relaxation modulus parameters. 
- Air void content: air voids are indispensable components of an asphalt mixture, which also act as initial flaws from which fracture occurs in the material. Therefore, the air void content directly affects the cracking performance of asphalt materials and must be formulated in the prediction model.

- Asphalt binder content: the main impact that the asphalt binder exerts on the cracking performance is its aging and increase of brittleness. A higher asphalt binder content results in more aging, which makes the mixture more brittle and less cracking-resistant.

- Aggregate gradation characteristics: the particle size distribution, or gradation, of aggregates affects almost every important property of asphalt mixtures, such as stiffness, durability, permeability, fatigue resistance, frictional resistance and moisture susceptibility (Roberts et al., 1996). As a result, the aggregate gradation characteristics must be taken into account. The specific procedure proposed to obtain the aggregate gradation characteristic parameters is as follows:

1) Obtain the aggregate gradation information from the mixture design.

2) Model the curve of the cumulative percent passing versus the sieve size using an appropriate mathematical function, as shown in Figure 6 for the two aggregate gradations used in Luo et al. (2013d):

$$
f(x)=\theta x^{\psi}
$$

where $x$ is the sieve size; $\theta$ is the aggregate scale parameter; and $\psi$ is the aggregate shape parameter.

Table 3 presents examples of the material properties listed above that are used to develop prediction models in the next step, as well as the values of $A^{\prime}$ and $n^{\prime}$ from the data sources mentioned above. 


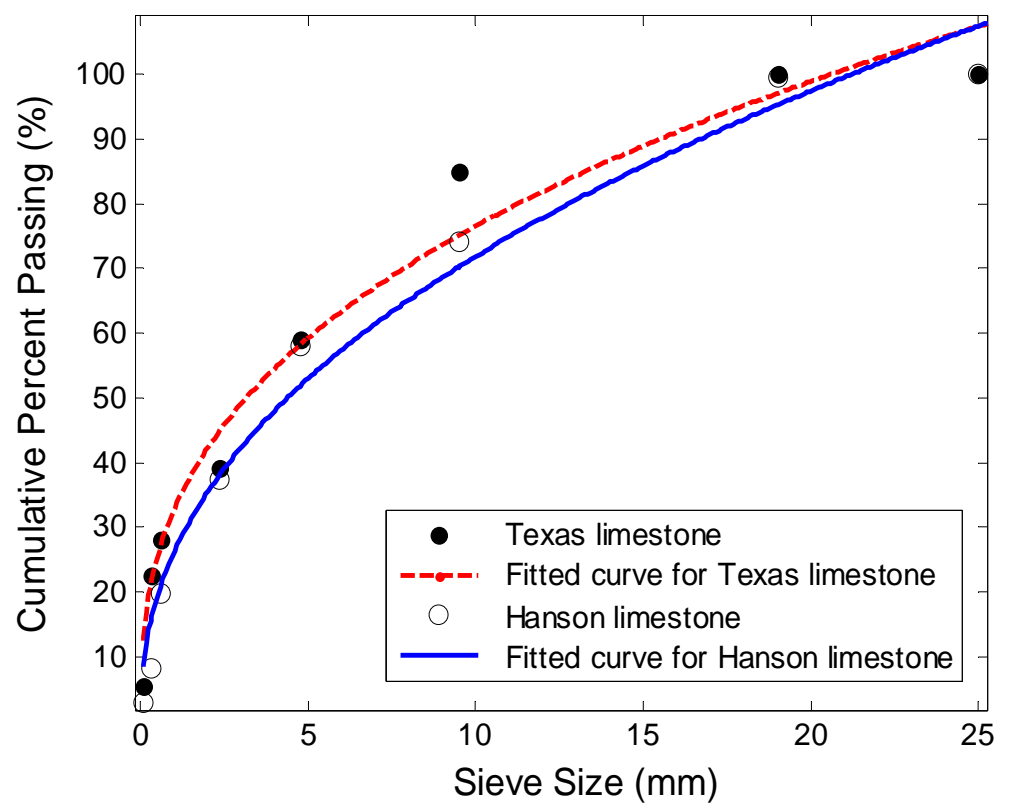

General model Power1: $\quad f(x)=\theta^{*} x^{\wedge} \psi$

Coefficients of Texas limestone (with 95\% confidence bounds):

$$
\begin{array}{lll}
\theta= & 32.65 & (25.06,40.23) \\
\psi= & 0.3699 & (0.2836,0.4562)
\end{array}
$$

Goodness of fit: R-square: 0.9738
Coefficients of Hanson limestone (with 95\% confidence bounds):

$$
\begin{array}{lll}
\theta= & 26.08 & (19.12,33.05) \\
\psi= & 0.4399 & (0.3431,0.5366)
\end{array}
$$

\begin{tabular}{|c|c|c|c|c|c|c|c|}
\hline \multirow{2}{*}{$\begin{array}{c}\text { Data } \\
\text { Source } \\
\text { and Test } \\
\text { Type }\end{array}$} & \multicolumn{2}{|c|}{$\begin{array}{c}\text { Fracture } \\
\text { Coefficients }\end{array}$} & \multicolumn{5}{|c|}{ Performance-Related Material Properties } \\
\hline & $A^{\prime}$ & $n^{\prime}$ & $\begin{array}{c}E_{1} \\
(\mathrm{MPa})\end{array}$ & $m$ & $\begin{array}{c}\text { Air } \\
\text { void } \\
\text { content } \\
(\%)\end{array}$ & $\begin{array}{c}\text { Asphalt } \\
\text { binder } \\
\text { content } \\
(\%)\end{array}$ & $\psi$ \\
\hline \multirow{2}{*}{$\begin{array}{c}\text { Jacobs } \\
(1995)\end{array}$} & $4.24 \times 10^{-7}$ & 2.55 & 412 & 0.181 & 2.0 & 6.0 & 0.399 \\
\hline & $3.29 \times 10^{-6}$ & 1.75 & 289 & 0.177 & 3.0 & 7.0 & 0.424 \\
\hline \multirow{3}{*}{$\begin{array}{c}\text { Dynamic } \\
\text { uniaxial } \\
\text { tensile } \\
\text { test }\end{array}$} & $5.18 \times 10^{-7}$ & 2.05 & 228 & 0.184 & 8.3 & 10.0 & 0.269 \\
\hline & $3.61 \times 10^{-8}$ & 3.05 & 312 & 0.177 & 7.9 & 6.8 & 0.387 \\
\hline & $2.34 \times 10^{-6}$ & 1.65 & 358 & 0.173 & 5.1 & 6.2 & 0.429 \\
\hline \multirow{2}{*}{$\begin{array}{l}\text { Luo et al. } \\
\text { (2013d) }\end{array}$} & $3.15 \times 10^{-16}$ & 9.80 & 6555 & 0.328 & 4.0 & 4.4 & 0.440 \\
\hline & $1.68 \times 10^{-8}$ & 3.47 & 35390 & 0.947 & 7.0 & 4.4 & 0.440 \\
\hline \multirow{2}{*}{$\begin{array}{l}\text { Controlle } \\
\text { d-strain } \\
\text { RDT test }\end{array}$} & $2.13 \times 10^{-12}$ & 7.42 & 4722 & 0.239 & 4.0 & 4.4 & 0.370 \\
\hline & $1.32 \times 10^{-12}$ & 7.36 & 1956 & 0.286 & 7.0 & 4.4 & 0.370 \\
\hline \multirow{2}{*}{$\begin{array}{l}\text { Gu et al. } \\
\text { (2014) }\end{array}$} & $1.35 \times 10^{-13}$ & 5.64 & 502 & 0.320 & 7.0 & 5.2 & 0.536 \\
\hline & $4.85 \times 10^{-11}$ & 4.90 & 448 & 0.310 & 7.0 & 5.2 & 0.536 \\
\hline \multirow{2}{*}{$\begin{array}{c}\text { Overlay } \\
\text { test }\end{array}$} & $1.01 \times 10^{-12}$ & 5.44 & 427 & 0.350 & 7.0 & 5.2 & 0.536 \\
\hline & $1.38 \times 10^{-14}$ & 5.90 & 481 & 0.290 & 7.0 & 5.2 & 0.536 \\
\hline
\end{tabular}

Goodness of fit: R-square: 0.9799

Figure 6. Determination of Aggregate Gradation Characteristic Parameters

Table 3. Examples of Values of Fracture Coefficients and Performance-Related Material Properties 


\section{Step 3. Develop prediction models of $A^{\prime}$ and $n^{\prime}$}

The multiple regression analysis is conducted to identify the relationship between $n^{\prime}$ and the selected performance-related material properties above. In order to develop a reliable and concise model for $n^{\prime}$, two important issues must be addressed: 1) the number of the variables; and 2) the formulation of the variables. The variables contained in the prediction model must be significant, and the formulation needs to ensure the highest R-squared value. An effective method to increase the R-squared value is to perform some transformations to certain variables. Based on these principles, the final expression of the prediction model of $n^{\prime}$ is:

$n^{\prime}=-16.052+0.135 A V \%+6.500 \ln (A B \%)+8.147 \psi+5.512 \frac{1}{m}-81.515\left(\frac{1}{E_{1}}\right)^{m}$

with $R^{2}=0.943$

where $A V \%$ is the air void content, in $\% ; A B \%$ is the asphalt binder content by weight of mixture, in \%; $\psi$ is the aggregate shape parameter; and $E_{1}$ and $m$ are relaxation modulus parameters, $E_{1}$ in MPa. The summary output of the multiple regression analysis is given in Table 4 . The $p$-values of all the variables are less than 0.05 , which indicates that they are significant at the 95 percent confidence level. Note that Equation 36 only contains one parameter, $\psi$, from the aggregate gradation model in Equation 35. This is because when both $\theta$ and $\psi$ are used to perform the multiple regression analysis, the $p$-value of $\theta$ is larger than 0.05 , so the aggregate scale parameter is not a significant variable and excluded from the prediction model. After obtaining $n^{\prime}$ by Equation 36, the other fracture coefficient $A^{\prime}$ is given by Equation 33. Figure 7 compares the predicted values by Equations 33 and 36 with the measured values. The R-squared values are satisfactory, so the proposed performance-related material properties as well as the prediction models can predict the fracture coefficients at acceptable accuracy. 
Table 4. Summary Output of Multiple Regression Analysis of n' Using Performance-Related Material Properties

\begin{tabular}{|c|c|c|c|c|c|c|c|}
\hline \multicolumn{2}{|c|}{ Regression Statistics } & \multicolumn{6}{|l|}{ ANOVA } \\
\hline Multiple R & 0.971 & & $d f$ & SS & MS & $F$ & $\begin{array}{c}\text { Significance } \\
F\end{array}$ \\
\hline R Square & 0.943 & Regression & 5 & 509.986 & 101.997 & $\begin{array}{l}274.07 \\
7\end{array}$ & $4.879 \mathrm{E}-50$ \\
\hline Standard Error & 0.610 & Residual & 83 & 30.888 & 0.372 & & \\
\hline Observations & 89 & Total & 88 & 540.875 & & & \\
\hline Variables & Coefficients & $\begin{array}{c}\text { Standard } \\
\text { Error }\end{array}$ & & Stat & $P$-value & $\begin{array}{c}\text { Lower } \\
95 \%\end{array}$ & $\begin{array}{l}\text { Upper } \\
95.0 \% \\
\end{array}$ \\
\hline Intercept & -16.052 & 2.049 & & 7.284 & $1.70 \mathrm{E}-10$ & -18.998 & -10.848 \\
\hline$A V \%$ & 0.135 & 0.033 & & 3.911 & $1.87 \mathrm{E}-04$ & 0.063 & 0.192 \\
\hline $\ln (A B \%)$ & 6.500 & 0.890 & & 5.887 & $1.01 \mathrm{E}-09$ & 4.359 & 7.899 \\
\hline$\psi$ & 8.147 & 1.416 & & 5.425 & $5.60 \mathrm{E}-07$ & 4.866 & 10.498 \\
\hline $1 / m$ & 5.512 & 0.267 & & 9.488 & $1.03 \mathrm{E}-32$ & 4.667 & 5.728 \\
\hline$\left(1 / E_{1}\right)^{m}$ & -81.515 & 3.821 & & 0.117 & $1.16 \mathrm{E}-33$ & -84.460 & -69.261 \\
\hline
\end{tabular}

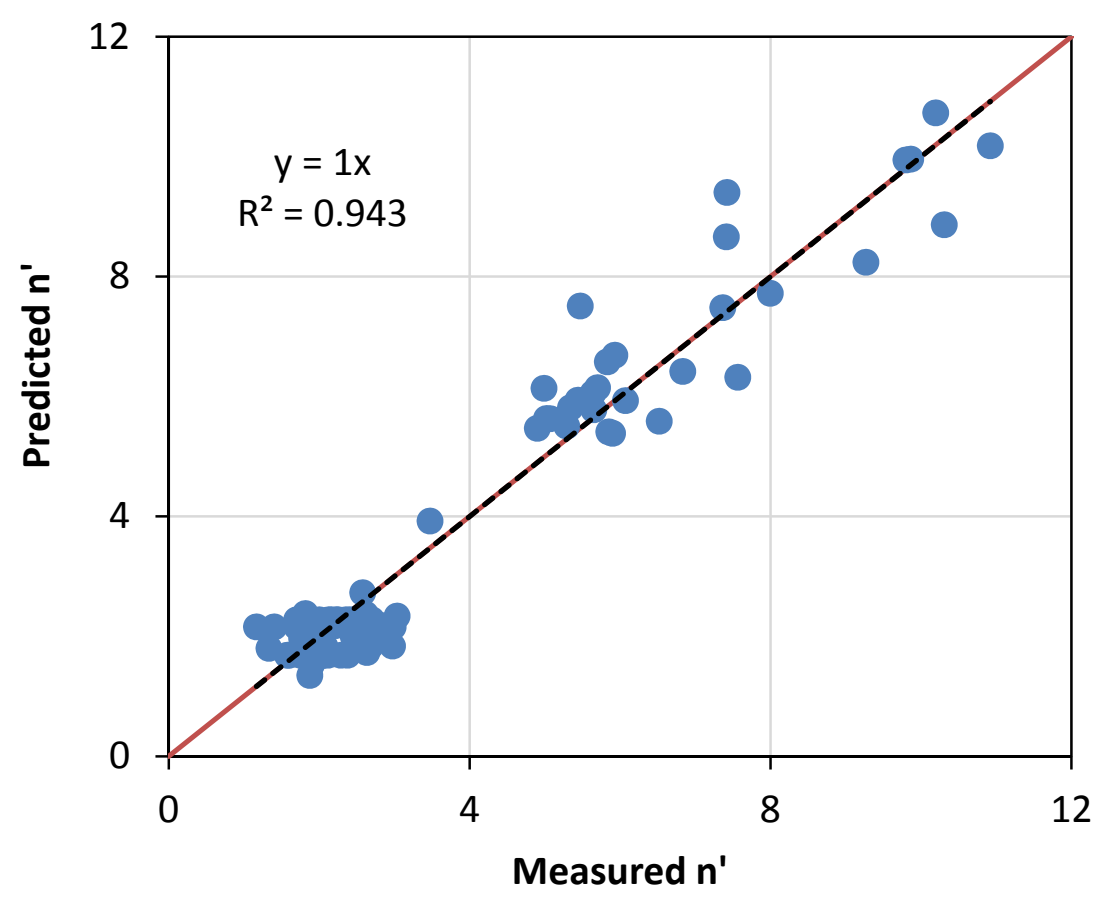

_Equivalence line $\quad$------ Linear (All of the data)

(a) n' 


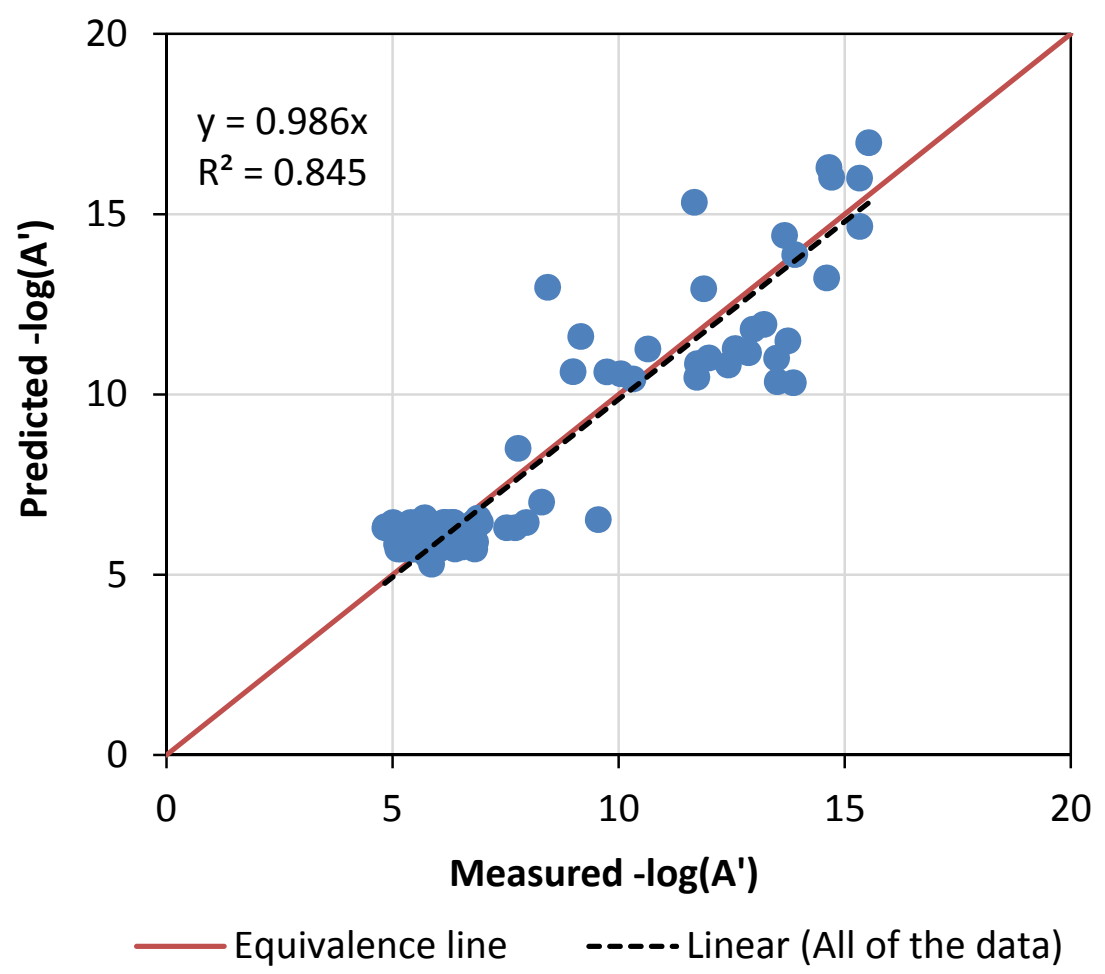

(b) $\mathrm{A}^{\prime}$

Figure 7. Comparison of Predicted and Measured Fracture Coefficients

\section{Case Study for Pavement Fatigue Performance Prediction}

The purpose of the case study is to illustrate the procedure and accuracy of the techniques proposed above to estimate fatigue cracking in asphalt pavements. Two cases are presented here:

1) Evaluation of laboratory fatigue resistance of asphalt mixtures; and

2) Assessment of field fatigue performance of asphalt pavements.

Furthermore, when the proposed techniques are applied to estimate the number of load repetitions to failure for an asphalt mixture or pavement, it offers a more distinct and direct definition of fatigue failure using the damage density or crack size, compared to the criteria used in S-VECD and PP-VECD. This application will be discussed in the future work.

\subsection{Evaluation of Laboratory Fatigue Resistance}

For laboratory-mixed-laboratory-compacted asphalt mixtures and laboratory testing, the accuracy of the calculations and predictions have been illustrated in 
Figures 3 and 7. The modified Paris' law with the aid of quasi-elastic simulation as well as $A^{\prime}$ and $n^{\prime}$ predictions is able to quantitatively estimate the cracking damage in an asphalt mixture. One set of data from Luo et al. (2013d) is used to demonstrate the procedure as follows step by step.

Step 1. Obtain the dynamic modulus (or relaxation modulus) data (e.g. the relaxation modulus master curve of the asphalt mixture denoted as "NuStar, $4 \%$, 6" in Figure 2)

Step 2. Calculate the representative elastic modulus in the quasi-elastic simulation (e.g. $E_{r e}=9387 \mathrm{MPa}$ for "NuStar, 4\%, 6" in Table 1)

Step 3. Calculate the DPW using the representative elastic modulus and the stress measured from the test.

Step 4. Determine the values of $a$ and $b$ by fitting the DPW versus N curve by a power function (e.g. for "NuStar, 4\%, 6", $a=0.0078, b=0.0681$ when the unit of the DPW is J).

Step 5. Determine the performance-related material properties in the prediction model of $n^{\prime}$ (e.g. $E_{1}=6555 \mathrm{MPa}, m=0.328, A V \%=4.0, A B \%=4.4$, and $\psi=0.440$ in Table 3)

Step 6. Calculate $n^{\prime}$ by Equation 36 and $A^{\prime}$ by Equation 33 (e.g. $n^{\prime}=9.94$, $\left.A^{\prime}=1.05 \times 10^{-16}\right)$.

Step 7. Substitute $a, b, A^{\prime}$, and $n^{\prime}$ into Equation 27 to obtain the damage density $\phi$.

A comparison of the predicted $\phi$ by Equation 27 and the measured values is presented in Figure 8. The prediction matches the measurement from the test very well. 


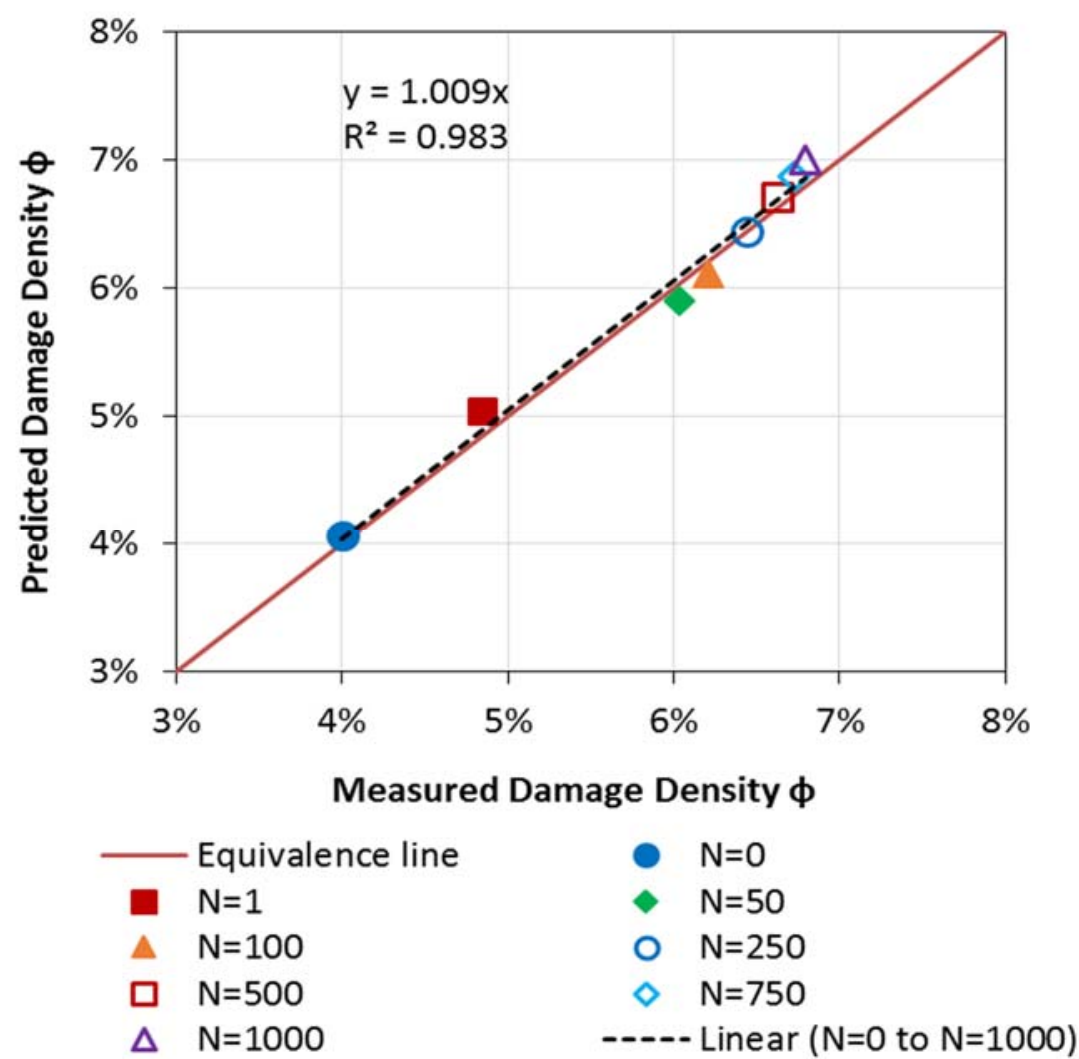

Figure 8. Comparison of Predicted and Measured Damage Density for an Example Asphalt Mixture

\subsection{Assessment of Field Fatigue Performance}

The field example is to demonstrate that the proposed tools are capable of using simple mixture information of field asphalt pavements to assess material fatigue resistance, which further serves as indicators of fatigue performance in field. Four field pavement sections with different fatigue performance are selected from the Long-Term Pavement Performance (LTPP) database. The procedure is elaborated as follows.

Step 1. Obtain the necessary data from the LTPP, including the dynamic modulus model coefficients, air void content, asphalt binder content, and aggregate gradation.

Step 2. Calculate the representative elastic modulus according to Equation 16 in the quasi-elastic simulation for each pavement section, in which the relaxation modulus is determined from the dynamic modulus master curve. The parameters and results are shown in Table 5.

Step 3. Calculate $J_{R}$ using the representative elastic modulus by Equation 25, in which $v$ is assumed to be $0.35 ; K_{I I}$ and $K_{I I I}$ are assumed to be zero; and $K_{I}$ 
is calculated by the following equation for penny-shaped cracks (Anderson, 2005):

$$
K_{I}=2 \sigma^{\infty} \sqrt{\frac{c}{\pi}}
$$

where $\sigma^{\infty}$ is the remote stress in a uniform state, i.e. pavement stress response due to the traffic; and $c$ is the average crack size. Assume that $\sigma^{\infty}$ is the same for all four pavement sections (this assumption is not valid in reality; however, the purpose of this case study is to evaluate the material fatigue resistance rather than the effect of pavement structure. Note that variations of traffic and climate are out of scope of this study).

Step 4. Determine the performance-related material properties in the prediction model of $n^{\prime}$, as shown in Table 5 .

Step 5. Calculate $n^{\prime}$ by Equation 36 and $A^{\prime}$ by Equation 33 for each pavement section, the values given in Table 5 .

Step 6. Substitute $J_{R}, A^{\prime}$, and $n^{\prime}$ into Equation 21 and utilize an iteration technique to compute $c$. More specifically,

1) When the load cycle is zero $(N=0), c$ is equal to the average air void size, which has a regression relation with the air void content as follows (Zhang et al., 2014):

$C_{0}=0.0037(A V \%)^{2}+0.0071(A V \%)+0.5583, \quad R^{2}=0.7431$

where $c_{0}$ is the average air void size. Then $K_{I}$ and $J_{R}$ corresponding to $c_{0}$ is computed by Equations 37 and 25, respectively.

2) When $N=1$, the crack increment in this cycle is calculated from Equation 21 as:

$$
\Delta c_{1}=A^{\prime}\left(J_{R 0}\right)^{n^{\prime}}
$$

where $\Delta c_{1}$ is the crack increment due to the first load cycle; and $J_{R 0}$ is the pseudo J-integral corresponding to $C_{0}$. Thus the average crack size becomes:

$$
c_{1}=c_{0}+\Delta c_{1}
$$


Then $K_{I}$ and $J_{R}$ corresponding to $C_{1}$ is updated by Equations 37 and 25 , respectively.

3) When $N=i$ ( $i$ is an arbitrary load cycle), the average crack size is calculated by:

$$
C_{i}=C_{i-1}+A^{\prime}\left(J_{R i-1}\right)^{n^{\prime}}
$$

Figure 9(a) presents the change of $C_{i}$ of the four pavement sections as the number of load cycles increases. Figure 9(b) shows the distress survey data extracted from the LTPP. According to Figure 9(b), the rank of the field fatigue performance is: section 51-0117, 12-0101, 48-0901, and 48-0903. The section 510117 has suffered severe fatigue cracking since 2001. The other three sections appear to start fatigue cracking around 2005 to 2006, and its development is relatively much slower. On the other hand, as shown in Figure 9(a), the predicted growth of the crack size of the materials from these four sections ranks in the same order, and with approximately similar relative cracking amounts as that observed in the field. The section 51-0117 is the most fracture susceptible and the first to have rapid growth of crack size. The sections 48-0901 and 48-0903 have similar cracking behaviors as predicted in Figure 9(a), also as observed in the field. The comparisons in Figure 9 demonstrate that the proposed techniques can serve as tools to rank and screen materials for better field fatigue performance. 
Table 5. Representative Elastic Modulus and Fracture Coefficients for LTPP Field Pavement Sections

\begin{tabular}{|c|c|c|c|c|c|c|c|c|}
\hline \multicolumn{9}{|c|}{ Raw Data Collection } \\
\hline $\begin{array}{l}\text { LTPP } \\
\text { Section }\end{array}$ & \multicolumn{2}{|c|}{$\begin{array}{c}\text { Dynamic } \\
\text { Modulus Model } \\
\text { Coefficients }\end{array}$} & \multicolumn{2}{|c|}{$\begin{array}{l}\text { Aggregate } \\
\text { Gradation }\end{array}$} & \multicolumn{2}{|c|}{$\begin{array}{c}\text { Air Void } \\
\text { Content (\%) }\end{array}$} & \multicolumn{2}{|c|}{$\begin{array}{l}\text { Asphalt Binder } \\
\text { Content }(\%)\end{array}$} \\
\hline $48-0901^{*}$ & \multirow{4}{*}{\multicolumn{2}{|c|}{$\begin{array}{l}\text { (details from } \\
\text { LTPP not } \\
\text { presented) }\end{array}$}} & \multirow{4}{*}{\multicolumn{2}{|c|}{$\begin{array}{l}\text { (details from } \\
\text { LTPP not } \\
\text { presented) }\end{array}$}} & \multicolumn{2}{|c|}{5.49} & \multicolumn{2}{|l|}{5.50} \\
\hline $48-0903$ & & & & & \multicolumn{2}{|c|}{5.52} & \multicolumn{2}{|l|}{5.40} \\
\hline $51^{*}-0117$ & & & & & \multicolumn{2}{|c|}{10.70} & \multicolumn{2}{|l|}{5.10} \\
\hline $12^{*}-0101$ & & & & & \multicolumn{2}{|c|}{3.89} & \multicolumn{2}{|l|}{5.20} \\
\hline \multicolumn{9}{|c|}{ Parameter Calculation and Prediction } \\
\hline \multirow{2}{*}{$\begin{array}{l}\text { LTPP } \\
\text { Section }\end{array}$} & \multicolumn{3}{|c|}{$\begin{array}{c}\text { Quasi-Elastic Simulation } \\
t_{p}=1 \mathrm{~s} ; \quad f=1 \mathrm{~Hz} ; \\
\text { temperature }=20^{\circ} \mathrm{C}\end{array}$} & \multicolumn{3}{|c|}{$\begin{array}{c}\text { Calculated } \\
\text { Performance-Related } \\
\text { Material Properties }\end{array}$} & \multicolumn{2}{|c|}{$\begin{array}{l}\text { Predicted Fracture } \\
\text { Coefficients }\end{array}$} \\
\hline & $\begin{array}{l}\left|E^{*}\right|_{f=\frac{1}{t_{p}}} \\
(\mathrm{MPa})\end{array}$ & $\begin{array}{c}E\left(t=\frac{t_{p}}{2}\right) \\
(\mathrm{MPa})\end{array}$ & $\begin{array}{c}E_{r e} \\
(\mathrm{MPa})\end{array}$ & $\begin{array}{c}E_{1} \\
(\mathrm{MPa})\end{array}$ & $m$ & $\psi$ & $A^{\prime}$ & $n^{\prime}$ \\
\hline 48-0901 & 10320 & 6238 & 8279 & 4520 & $\begin{array}{c}0.31 \\
1\end{array}$ & $\begin{array}{c}0.53 \\
0\end{array}$ & $3.99 \times 10^{-19}$ & 11.87 \\
\hline 48-0903 & 10906 & 6354 & 8630 & 4858 & $\begin{array}{c}0.30 \\
6\end{array}$ & $\begin{array}{c}0.53 \\
8\end{array}$ & $2.90 \times 10^{-19}$ & 11.98 \\
\hline $51-0117$ & 6452 & 3000 & 4726 & 1566 & $\begin{array}{c}0.24 \\
9\end{array}$ & $\begin{array}{c}0.50 \\
1\end{array}$ & $9.82 \times 10^{-16}$ & 9.14 \\
\hline 12-0101 & 6392 & 2749 & 4571 & 1368 & $\begin{array}{c}0.24 \\
4\end{array}$ & $\begin{array}{c}0.52 \\
1\end{array}$ & $2.40 \times 10^{-14}$ & 8.03 \\
\hline
\end{tabular}

": "48" is LTPP state code, indicating Texas; "0901" is test section identification number assigned by LTPP. "51" indicates Virginia. "12" indicates Florida.

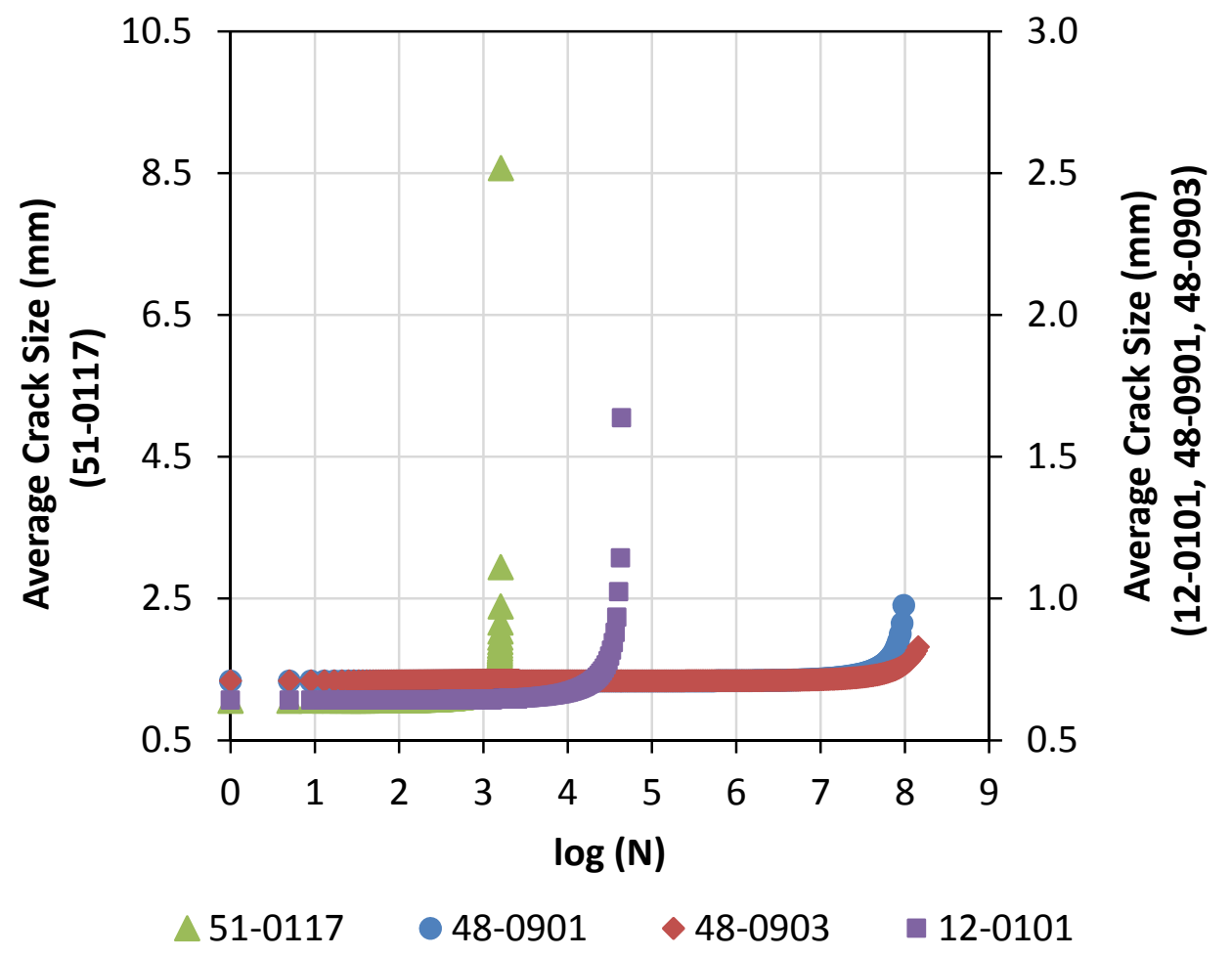

(a) Predicted by the Proposed Techniques 


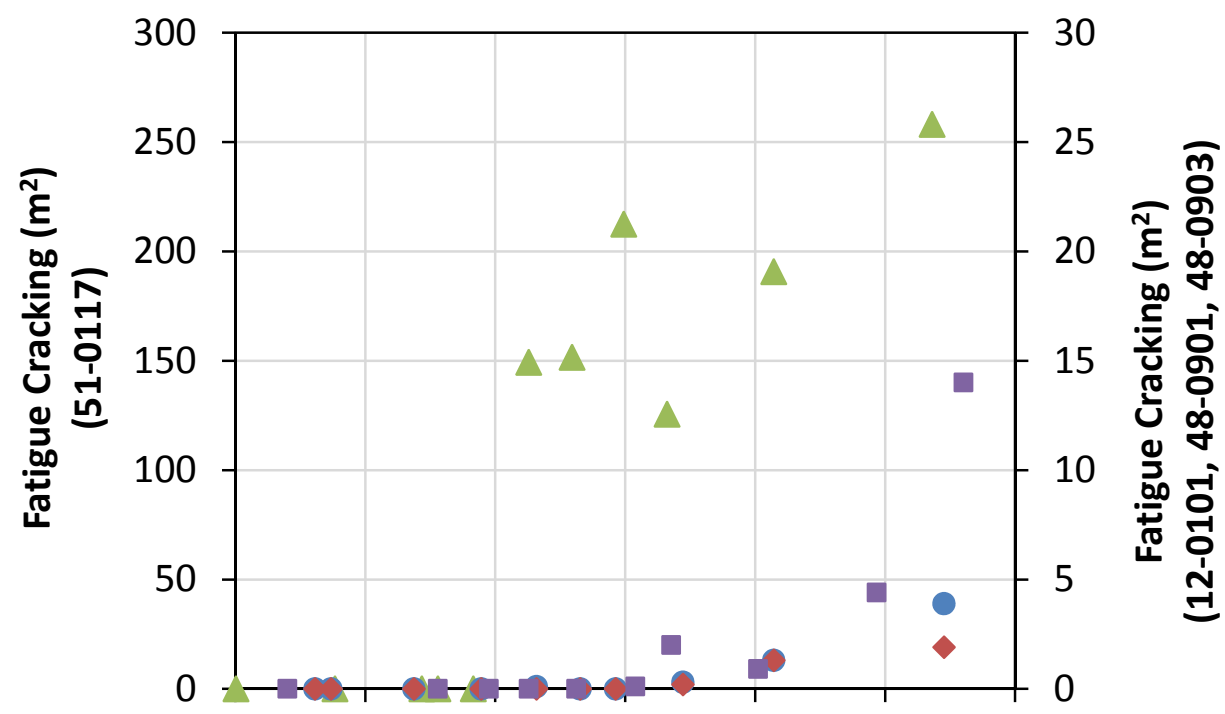

Oct-95 Jul-98 Apr-01 Jan-04 Oct-06 Jul-09 Apr-12

Survery Date (year)

$\triangle 51-0117$ ๑ 48-0901 $\triangleleft 48-0903 \quad$ 12-0101

(b) Distress Survey in the Field

Figure 9. Comparison of Predicted and Measured Fatigue Cracking for LTPP Pavement Sections

\section{Summary and Future Work}

Pavement analysis and design for fatigue cracking involves a number of practical problems like material assessment/screening and performance prediction. An effective and convenient method to provide such information with satisfactory accuracy is undoubtedly helpful to the decision-making process. This study presents two techniques to enable the analyses and designs to be performed in a mechanics-aided way to meet these demands.

- The first technique, quasi-elastic simulation, provides a way to conduct pseudo analysis (i.e., viscoelastic to elastic conversion) for damage using the basic viscoelastic property: dynamic modulus or relaxation modulus. The representative elastic modulus formulated by the dynamic modulus and relaxation modulus is assigned as the reference modulus when calculating the pseudo strain or pseudo energy. The physical significance of adopting the representative elastic modulus is clarified through the theoretical explanations and experimental validations.

- The second technique to simplify the prediction of fatigue cracking makes it possible to estimate the damage density or crack size through the 
modified Paris' law without performing fatigue tests. The modified Paris' law replaces the conventional stress intensity factor/J-integral with the pseudo J-integral, which is easily obtained via the quasi-elastic simulation. The modified Paris' law coefficients, normally determined from cyclic load tests, are estimated using the prediction models formulated with the performance-related material properties, including the relaxation modulus, air void content, asphalt binder content, and aggregate gradation.

Sufficient data are collected to develop such prediction models and the Rsquared values are around 0.9 .

- The case studies illustrate the applicability of the proposed techniques in pavement analysis and design. They are able to predict fatigue resistance of asphalt mixtures with or without laboratory testing with high accuracy. They can serve as tools to rank/screen materials and indicate fatigue performance of asphalt pavements in the field through mixture design information and dynamic modulus test data.

The work presented in this study serves as a preliminary exploration of implementing the pseudo J-integral based Paris' law to evaluate and predict fatigue cracking in asphalt mixtures and pavements. There are more refinements that can be expected in the future. For example, the performance-related properties chosen to formulate the prediction models for the modified Paris' law coefficients could be substituted through a direct usage of the dynamic modulus instead of the relaxation modulus, or through an improved aggregate gradation model to better distinguish the characteristics of aggregates. There are more applications that will be investigated in the future as well. For instance, the predicted fatigue cracking in terms of the damage density or crack size offers a distinct criterion that defines fatigue failure directly by its physical significance. As shown in the two cases above, once the $\phi$-versus- $N$ or $c$-versus- $N$ curve is obtained, the number of load repetitions to failure, $N_{f}$ can be identified with a prescribed value of $\phi$ or $c$. For laboratory tests, $N_{f}$ is read directly from the $\phi$ versus- $N$ or $c$-versus- $N$ curve. For field performance prediction, $N_{f}$ from the $\phi$ versus- $N$ or $c$-versus- $N$ curve is translated to its corresponding field value after calibration. 


\section{References}

Anderson TL (2005) Fracture mechanics: fundamentals and applications. CRC press, Boca Raton, Florida.

ARA, Inc. (2004) Guide for mechanistic-empirical design of new and rehabilitated pavement structure. Draft Final Report 1-37A, National Cooperative Highway Research Program, Transportation Research Board, Washington, D.C.

ASTM (2003) Standard test method for dynamic modulus of asphalt mixtures. ASTM D3497, West Conshohocken, PA.

Christensen DW, Bonaquist R (2005). Practical application of continuum damage theory to fatigue phenomena in asphalt concrete mixtures. J. Assoc. Asphalt Paving Technol. 74:963-1002.

Collop AC, Scarpas A, Kasbergen C, de Bondt A (2003) Development and finite element implementation of stress-dependent elastoviscoplastic constitutive model with damage for asphalt. Transp. Res. Rec. 1832:96-104.

Dai Q, Sadd M, Parameswaran V, Shukla A (2005) Prediction of damage behaviors in asphalt materials using a micromechanical finite-element model and image analysis. J. Eng. Mech. 131(7): 668-677.

Findley WN, Lai JS, Onaran K (1989) Creep and Relaxation of Nonlinear Viscoelastic Materials: with an Introduction to Linear Viscoelasticity. Dover Publications, New York.

Gu F, Zhang Y, Luo X, Luo R, Lytton RL (2014) Improved methodology to evaluate fracture properties of warm mix asphalt using overlay test. Transp. Res. Rec. in press.

Hu S, Zhou F, and Scullion T (2014) Development of Texas Mechanistic-Empirical Flexible Pavement Design System (TxME). FHWA/TX-14/0-6622-2, Texas A\&M Transportation Institute, College Station, TX

Jacobs MMJ (1995) Crack growth in asphaltic mixes. PhD dissertation, the Delft University of Technology, The Netherlands.

Jones DR (1993) SHRP Report A-645: Materials Reference Library: Asphalt Cements: A Concise Data Compilation. TRB, National Research Council, Washington, D.C.

Kim YR, Wen H (2002) Fracture energy from indirect tension testing. J. Assoc. Asphalt Paving Technol 71: 779-793.

Kuai H, Lee HJ, Zi G, Mun S (2009) Application of generalized J-integral to crack propagation modeling of asphalt concrete under repeated loading. Transp. Res. Rec. 2127:72-81.

Kutay ME, Gibson N, Youtcheff J, Dongré R (2009) Use of small samples to predict fatigue lives of field cores. Transp. Res. Rec. 2127: 90-97.

Luo X, Luo R, Lytton RL (2013a) Characterization of fatigue damage in asphalt mixtures using pseudo strain energy. J Mater Civil Eng 25(2):208-218.

Luo X, Luo R, Lytton RL (2013b) Characterization of asphalt mixtures using controlled-strain repeated direct tension test. J Mater Civil Eng, 25(2):194-207.

Luo X, Luo R, Lytton RL (2013c) Characterization of recovery properties of asphalt mixtures. Constr. Build. Mater. 48:610-621. 
Luo X, Luo R, Lytton RL (2013d) A modified paris' law to predict entire crack growth in asphalt mixtures. Transp. Res. Rec 2373:54-62.

Luo X, Luo R, Lytton RL (2014) Energy-based crack initiation criterion for viscoelastoplastic materials with distributed cracks. J Eng Mech. 141(2):04014114.

Lytton RL, Roque RL, Uzan J, Hiltunen DR, Fernando E, Stoffels SM (1993) Performance models and validation of test results. Final Report, Asphalt Project A-005, Strategic Highway Research Program, National Research Council, Washington, DC.

Park SW, Kim YR, Schapery RA (1996) A viscoelastic continuum damage model and its application to uniaxial behavior of asphalt concrete. Mech. Mater. 24(4): 241-255.

Roberts FL, Kandhal PS, Brown ER, Lee DY, Kennedy TW (1996) Hot mix asphalt materials, mixture design, and construction. National Asphalt Paving Association Education Foundation, Lanham, MD.

Rowe GM (1993) Performance of asphalt mixtures in the trapezoidal fatigue test. J. Assoc. Asphalt Paving Technol. 62: $344-384$.

Schapery RA (1984) Correspondence principles and a generalized J integral for large deformation and fracture analysis of viscoelastic media. Int J Fracture 25:195-223.

Underwood BS, Kim YR (2009) Determination of the appropriate representative elastic modulus for asphalt concrete. Int J Pave Eng 10(2): 77-86.

Underwood BS, Baek C, Kim YR (2012) Simplified viscoelastic continuum damage model as platform for asphalt concrete fatigue analysis. Transp. Res. Rec. 2296:36-45.

Zhang Y, Luo R, Lytton RL (2012) Characterizing permanent deformation and fracture of asphalt mixtures by using compressive dynamic modulus tests. J Mater Civil Eng 24(7): 898-906.

Zhang Y, Luo X, Luo R, Lytton RL (2014) Crack initiation in asphalt mixtures under external compressive loads. Constr. Build. Mater. 72:94-103.

Zhang Z, Roque R, Birgisson B (2001) Evaluation of laboratory-measured crack growth rate for asphalt mixtures. Transp. Res. Rec. 767:67-75.

Zhou F, Fernando E, Scullion T (2010) Development, calibration, and validation of performance prediction models for the Texas M-E flexible pavement design system. FHWA/TX-10/05798-2, Texas A\&M Transportation Institute, College Station, TX 


\section{List of Figures}

Figure 1. Decomposition of Typical Haversine-Shaped Strain Pulse

Figure 2. Examples of Relaxation Modulus Master Curves at Reference Temperature $20^{\circ} \mathrm{C}$

Figure 3. Comparison of Critical Nonlinear Viscoelastic Properties and Representative Elastic Moduli

Figure 4. Example of Dynamic Modulus Master Curve at Reference Temperature $25^{\circ} \mathrm{C}$

Figure 5. Relationship between Fracture Coefficients $A$ ' and $n$ '

Figure 6. Determination of Aggregate Gradation Characteristic Parameters

Figure 7. Comparison of Predicted and Measured Fracture Coefficients

Figure 8. Comparison of Predicted and Measured Damage Density for an

Example Asphalt Mixture

Figure 9. Comparison of Predicted and Measured Fatigue Cracking for LTPP Pavement Sections 